\title{
A review and empirical study of the composite scales of the Das-Naglieri cognitive assessment system
}

\author{
Simon M McCrea \\ JP Das Developmental Disabilities \\ Center, Department of Educational \\ Psychology, Faculty of Education, \\ University of Alberta, Edmonton, \\ Alberta, Canada
}

\begin{abstract}
Alexander Luria's model of the working brain consisting of three functional units was formulated through the examination of hundreds of focal brain-injury patients. Several psychometric instruments based on Luria's syndrome analysis and accompanying qualitative tasks have been developed since the 1970s. In the mid-1970s, JP Das and colleagues defined a specific cognitive processes model based directly on Luria's two coding units termed simultaneous and successive by studying diverse cross-cultural, ability, and socioeconomic strata. The cognitive assessment system is based on the PASS model of cognitive processes and consists of four composite scales of Planning-Attention-Simultaneous-Successive (PASS) devised by Naglieri and Das in 1997. Das and colleagues developed the two new scales of planning and attention to more closely model Luria's theory of higher cortical functions. In this paper a theoretical review of Luria's theory, Das and colleagues elaboration of Luria's model, and the neural correlates of PASS composite scales based on extant studies is summarized. A brief empirical study of the neuropsychological specificity of the PASS composite scales in a sample of 33 focal cortical stroke patients using cluster analysis is then discussed. Planning and simultaneous were sensitive to right hemisphere lesions. These findings were integrated with recent functional neuroimaging studies of PASS scales. In sum it was found that simultaneous is strongly dependent on dual bilateral occipitoparietal interhemispheric coordination whereas successive demonstrated left frontotemporal specificity with some evidence of interhemispheric coordination across the prefrontal cortex. Hence, support for the validity of the PASS composite scales was found as well as for the axiom of the independence of code content from code type originally specified in 1994 by Das, Naglieri, and Kirby.
\end{abstract}

Keywords: stroke, focal cortical lesions, Alexander Luria, syndrome analysis, Planning-AttentionSimultaneous-Successive (PASS), cognitive assessment system, hierarchical agglomerative cluster analysis, specificity

\section{Introduction}

The cognitive assessment system (CAS) has now been used in neuropsychological assessment contexts for both children and adults ${ }^{1}$ although it was not initially designed as a neuropsychological instrument. The CAS is modeled on the Planning-Arousal/ Attention-Simultaneous-Successive (PASS) theory of cognitive processes. ${ }^{2-5}$ The PASS model is an elaboration, standardization, and development of core concepts of Luria's qualitative theory in the context of Western neuropsychology's demands for quantitative methods, sensitivity, and specificity. ${ }^{6,7}$ The CAS has a broad range of complexity of items within subtests, several different types of tasks within each composite scale, qualitative analysis, sensitivity, excellent test and retest characteristics as well as reliability and acceptable construct validity parameters. ${ }^{5}$ A Japanese version of the CAS has recently been published ${ }^{8}$ in addition to earlier clinical trials with a prior Spanish version. 
Previous attempts to operationalize Luria's theory include the Luria-Nebraska Neuropsychological Battery $(\mathrm{LNNB})^{9}$ in which 11 clinical scales were constructed from 269 pass-fail individual items. The LNNB has met with mixed reviews since establishing split-half reliability is not possible with 269 qualitatively different items. ${ }^{10}$ The LNNB was standardized on a sample of 50 subjects (mean age $=42$ ) and educational level (12 years) and unfortunately subjects with nonlocalized, diffuse lesions, or no lesions at all were included in the reference sample. Although the LNNB purports to separate brain-damaged from nonbrain-damaged subjects, the data concerning this battery's efficacy in localizing subtle brain damage within specific regions of each hemisphere is limited. The scales do not have adequate content validity, there is an over emphasis on verbal responding, tasks are confounded with other cognitive functions, nor are all major neuropsychological functions examined, and finally the LNNB does not lend itself to qualitative interpretation in its scoring system. ${ }^{11}$ Additional studies have shown that the LNNB does not appear to be able to identify lesion laterality to a satisfactory degree ${ }^{12}$ although there have been subsequent attempts to comprehensively summarize Luria's clinical-theoretical approach to assist with the interpretation of the results. ${ }^{13}$

The Kaufman Assessment Battery for Children (K-ABC) is yet another cognitive model that is based on Luria' $\mathrm{s}^{6,14}$ and Das, Kirby, and Jarman' ${ }^{15}$ simultaneous and successive cognitive processes theory. ${ }^{16}$ However, unlike the DN-CAS or the LNNB the K-ABC has not been scaled for use in young adults. Of the 10 mental processing scales of the $\mathrm{K}-\mathrm{ABC}$ seven are labeled "simultaneous" and three are "sequential". The simultaneous tasks include: (i) object naming from partial view of a picture through a hole; (ii) arrangement of photos like picture arrangement of the WAIS; (iii) gestalt closure; (iv) a variation of Koh's block design using triangles; (v) matrices; (vi) spatial memory; and (vii) face recognition. The sequential tasks include: (i) hand movements; (ii) digit repetition; and finally (iii) silhouette seriation via pointing. ${ }^{17}$

The K-ABC is purported to break down into left (analytical-sequential) and right (gestalt-holisticsimultaneous) hemisphere functions ${ }^{16}$ as noted by Spreen and Strauss. ${ }^{18}$ However Das, Kirby, and Jarman note that visuospatial functions can be processed successively and that auditory information can be processed simultaneously. ${ }^{19}$ That is, simultaneous is not synonymous with nonverbal visual processing nor is successive by necessity the same as verbal processing! This point is illustrated in Das and colleagues's ${ }^{15,19}$ theory by showing that simultaneous aspects of grammar-based spatial language can occur in addition to the reverse scenario of successive nonlinguistic seriationbased tasks such as in Corsi block tapping. ${ }^{20}$

Moreover, Luria did not emphasize that these two types of information integration and syntheses were necessarily lateralizable; although the $\mathrm{K}-\mathrm{ABC}$ does include a mix of both verbal and nonverbal simultaneous and successive tasks. ${ }^{6}$ Donders noted that, in a sample of 43 children with traumatic brain injury, the $\mathrm{K}-\mathrm{ABC}$ did not discriminate any better than the revised Wechsler Intelligence Scale for Children (WISC-R). ${ }^{21}$ Morris and Bigler were more optimistic in their appraisal and found some degree of concordance of lateralization of $\mathrm{K}-\mathrm{ABC}$ dimensions in 79 neurologically impaired children based on patterns of localization inferred from mainstream neuropsychological tests. ${ }^{22}$ However, caution was urged in terms of the generalizability of these findings since the results were based on the levels of performance on other marker neuropsychological tests and were not based on structural neuroimaging findings per se.

Gutentag, Naglieri, and Yeates first demonstrated that both PASS scales and select subtests of the CAS reliably discriminated between adolescents with traumatic brain injury and controls..$^{23}$ Moreover, the PASS scales and the CAS subtests were found to be of diagnostic utility in distinguishing between younger and older Down's syndrome patients with and without organic dementia of the Alzheimer's type (DAT). This DAT patient data converged with the findings from the standard Mattis Dementia Rating Scale and Peabody Picture Vocabulary Test-Revised score patterns. ${ }^{24}$

Subsequently Wysocki and colleagues successfully implemented the CAS along with other standard neuropsychological instruments in the assessment of children with diabetic symptomatology. ${ }^{25}$ It was found that the CAS subtests and PASS scales were sensitive enough to be used for neuropharmacological baseline purposes after 9 and 18 months of medication for severe diabetes. Ryan, Atkinson, and Dunham's study of 262 adults found that the CAS's planning subtests tapping executive functions were sensitive and difficult enough to discriminate among college student's cognitive functioning. ${ }^{26}$ The latter finding is important in supporting the conclusion that the broad range of difficulty of items within subtests and composite scales could render this battery useful in adult bedside neuropsychological populations. Davis and colleagues found that a five-days-per-week, four-month-long intensive exercise program for obese elementary school children likely 
provided cerebrovasculature benefits and hence enhanced cognitive functioning as measured by the Das-Naglieri (DN) CAS planning composite scale. ${ }^{27}$

In response to critics, Haddad noted that the qualitativelyrated planning tasks of the CAS were not tapping only speed of processing and definitively required the use of cognitive strategies for optimal completion of these items. ${ }^{28}$ This study demonstrated that the CAS planning subtests are robust executive functions tasks and that the Luria-modeled qualitative descriptions of performance are useful and meaningful for interpretation of composite scales and perhaps implementation of remedial programs. ${ }^{5}$ Perez-Alvarez and colleagues found that 35 patients treated for idiopathic epilepsies with the anticonvulsant topiramate for six months demonstrated significant improvement on the planning scale composite. ${ }^{29}$ Subsequently Mack and colleagues found that surgically restoring portal blood flow to the liver in children with primary extrahepatic thrombosis (and thus at risk for hepatic central nervous system [CNS] neurotoxicity), improved performance on the attention composite scale of the $\mathrm{CAS}^{30}$

Using Luria's syndrome analysis method, the concordance between PASS scale scores and cognitive and linguistic impairments have also been studied. ${ }^{6}$ Perez-Alvarez and Timoneda-Gallart found that planning was specifically impaired in a large attention-deficit hyperactivity disorder (ADHD) Spanish sample. ${ }^{31}$ In two South African case studies Jordaan and colleagues determined that a subject with specific language impairment (SLI) presented with a deficiency in successive processing and had difficulty in acquiring the surface features of both English and Afrikaans. ${ }^{32}$ In contrast a subject with a semantic-pragmatic disorder (SPD) demonstrated a planning and attention deficiency with strength in successive processing and competency in both languages. In a Dutch sample, Van Luit, Kroesbergen, and Naglieri found that subjects with ADHD demonstrated significantly lower scores on planning and attention scales and normal scores on simultaneous and successive scales. ${ }^{33}$

Finally Naglieri and colleagues found a number of clinically significant correlations between CAS composite scales and the Conners' Continuous Performance Test (CPT). ${ }^{34}$ There were in fact more clinically significant and meaningful correlation indicators with the CAS's PASS scales and the CPT than with the newly standardized WISC-III and the CPT. This is particularly noteworthy with respect to the study of learning disabilities since the CPT is one of the most widely-used marker tests of
ADHD diagnosis. Collectively these neuropsychological and learning disability cross-cultural studies suggest that across ages, language, cultural, and neurological impairments there are convergent findings which could imply construct validity of the PASS model.

\section{Purpose of the study}

Hence, there will be five inter-related purposes to this theoretical review and accompanying short empirical study. Firstly, psychometric instantiations spanning the 1970's to more recent elaborations of Luria's qualitative method and validity studies with the CAS have been compared and contrasted. Secondly, a brief overview of the sociohistorical and neuropsychological background surrounding Alexander Luria's theory of higher cortical functions will be undertaken in the context of Soviet nonreductively materialist psychology. Thirdly, Das and Naglieri's specific instantiation of Luria's theory in the PASS model of cognitive functions will be discussed specifically with reference to the CAS. Fourthly, core differences between the coding processes of simultaneous and successive will be contrasted with other dual cognitive process models in cognitive psychology and the functional neuroanatomical correlates of these processes will be summarized. Finally, a brief empirical study examining the construct validity of the DN-CAS composite PASS scales will be undertaken in a sample of focal cortical lesion stroke patients and the overall utility of this unique neuropsychological instrument will be discussed. Future directions in the further development of this model that attempts to bridge individual differences, neuropsychology, and cognitive and behavioral rehabilitation will be highlighted.

\section{Luria's theory of higher cortical functions}

Eilam (2003) notes that the philosophical foundations of Luria's research program was based on a cultural-historical psychological theory that was nonreductively materialist in its core assumptions..$^{35}$ Along with Vygotsky and Leont'ev, these three investigators developed a comprehensive theory of consciousness as a phenomenon in which mental functions reflect social relations as manifested by human action in a world of concrete and theoretical objects. ${ }^{36}$ For these theorists, language was the most important cultural means that affects the contents and structure of cognitive development. That is, when experts or adults name objects they also implicitly define the a priori relationships between these objects such that a nonacculturated person or child will 
invariantly create new ways of representing reality. In this context the appropriation of cultural means requires the use of (i) not only objects (be these concrete tools or abstract linguistic tools), but more importantly (ii) the acquisition of this object's sociocultural meaning in context. ${ }^{35}$

In Luria's theory then appropriation of cultural tools are essential for the establishment of functional connections between localized modules and thus in producing higher cognitive functions through ontogeny. These higher cortical functions were first to appear on the interpsychological sociological plane and only then on the intrapsychological plane as plans that may be used to direct activity of the organism. ${ }^{37}$ Therefore in this analysis a person's higher mental functions do not originate solely from within the totality of the CNS but rather is conceived as a direct consequence of internalization and in essence reflection of the sociocultural environment and milieu. This theoretical proposition suggests that higher mental functions do not in and of themselves arise solely as a consequence of the genetic constitution of the individual. Rather as a consequence of the mediation of sociocultural products and signs there is a resultant development of a capacity for the human organism to perform abstract planful activity. Thus these reflections of the sociocultural milieu and historical accumulation of knowledge and skills of a particular culture have both (i) material and (ii) theoretical correlates that develop and form during the history of human social life.

Since the acquisition of these cultural means differ in terms of their historical periods and different cultures there was no fixed innately determined localization of higher mental functions in brain structure. ${ }^{35}$ Meccaci's review of Luria's unitary view of brain and mind provides an excellent example in the Japanese writing systems. ${ }^{38}$ The two Japanese writing systems have entirely different functional organizations than Western writing systems. ${ }^{39}$ As Meccaci notes, according to Luria's theory "...the development of these new 'higher' functional systems implies a reorganization of 'lower' cortical functions, a kind of Gestalt-like restructuration where inferior components acquire a new functional [meaning] at the moment in which they become part of the new superior organization...." (p. 818). ${ }^{38}$

\section{Das and Naglieri's PASS model of cognitive functions}

Das describes a multidimensional view of cognitive processes ${ }^{4}$ based on Luria's theory ${ }^{6,7}$ as consisting of four functions including: planning, arousal-attention, simultaneous, and successive syntheses. In this model, planning is required when for instance an individual makes decisions about how to solve a problem, carry out a novel activity, or compose a narrative. Attention-arousal is the process that allows a person to selectively attend to some stimuli while ignoring others, resist distractions, and maintain vigilance. Simultaneous processing integrates percepts into groups and as a result stimuli are conceptualized as a whole, with each piece being related to the others. Finally successive processing involves integrating stimuli into a specific serial order and is exemplified in processing words in order to determine their function as in syntactic comprehension. ${ }^{4}$

The theory links the four processes with particular regions of the brain. Planning is associated with the frontal lobes, attention-arousal with the reticular activating system, and its associated brainstem catecholaminergic projections throughout the cortex. The two coding units simultaneous and successive are associated with occipito-temporoparietal junction and frontotemporal and perisylvian opercular regions, respectively. This PASS model is directly based on Luria's $\mathrm{s}^{6,7}$ model of higher cortical functions in man. The PASS model is an elaboration of Das, Kirby, and Jarman's ${ }^{19}$ early psychometric and cross-cultural work demonstrating two coding units as well as with subsequent studies incorporating planning and attention in Luria's complete model of higher cortical functions. . $^{2,40,41}$

\section{Planning and the prefrontal cortex}

Perhaps the most important and overlooked and yet still highly relevant contributions of Luria's work to neuropsychology have been in the area of problem-solving and frontal lobe functions. ${ }^{42,43}$ Luria's qualitative methods and syndrome analysis have been influential in the development of subsequent models of these processes. ${ }^{4-46}$ In these later works the rudiments of Luria's model encompassing goalweighting, anticipatory processes, evaluation, feedback, and corollary discharge between motor and sensory systems are present. These components of planning actually antedated modern notions of a hierarchical distributed control system or supervisory attentional system (SAS) associated with the prefrontal cortex. These control processes appear to be essential in bridging the sociocultural contigencies of environmental contexts with self-directed organized, purposeful, and planful behaviors. A full discussion of Luria's theory of planning is beyond the scope of this article. Readers are directed to Das, Kar, and Parrila's text ${ }^{41}$ for an extensive review of Alexander Luria's and JP Das and colleagues's cognitive models of planning as well as being presented 
with theoretical integration with more recent cognitive psychological and cognitive neuroscience theories.

\section{Attention-arousal and the reticulothalamic formation}

Das's description of the arousal-attention unit contains the brainstem reticular activating system (RAS) extending from the spinal cord up to inhibitory nuclei within the thalamus. ${ }^{4}$ The RAS contains both ascending and descending projections from the forebrain and pyramidal tracts acting together on sensory relay nuclei. The RAS innervates many regions of the CNS and thus represents the major source of general regulatory systems associated with 'brain excitability'. Moreover, reticular neurons are not specialized for relaying and analyzing signals that are exclusively transmitted within a particular modality such as vision, auditory sensations or touch. The functional importance of the RAS was first described by Moruzzi and Mangoun in 1949 and it was shown that it induces arousing effects on the thalamus of the diencephalon and cortex. ${ }^{47}$ A more contemporary view of the RAS shows that it is not a 'nonspecific' and undifferentiated structure as originally proposed by Luria ${ }^{6,7}$ and that instead different neurotransmitter systems and their associated nuclei projections exert arousing effects on the diencephalon and telencephalon in specific manners. ${ }^{48}$

Two cholinergic pathways have been described and are depicted in green in Figure 1. Cholinergic mesopontine cells (PN) directly innervate the centrolateral nucleus (CL) of the thalamus and constitute about $30 \%$ of cholinergic synapses. In contrast, projections originating within the basal nucleus of Meynert (BN) in the forebrain send projections directly throughout the cortex via the cingulate bundle and constitute the remaining $70 \%$ of synapses. In addition, pontine-thalamic cholinergic projections within the $\mathrm{CL}$ of the thalamus relay modulated signals throughout the cortex via glutaminergic long-range excitatory amino acid synapses. ${ }^{48}$ The latter glutaminergic excitatory synaptic projections throughout the cortex are depicted in light blue in Figure 1. Finally, BN or substantia innominata located in the anterior perforated substance sends projections back to the reticular thalamic nucleus (RE) of the thalamus. These two cholinergic systems

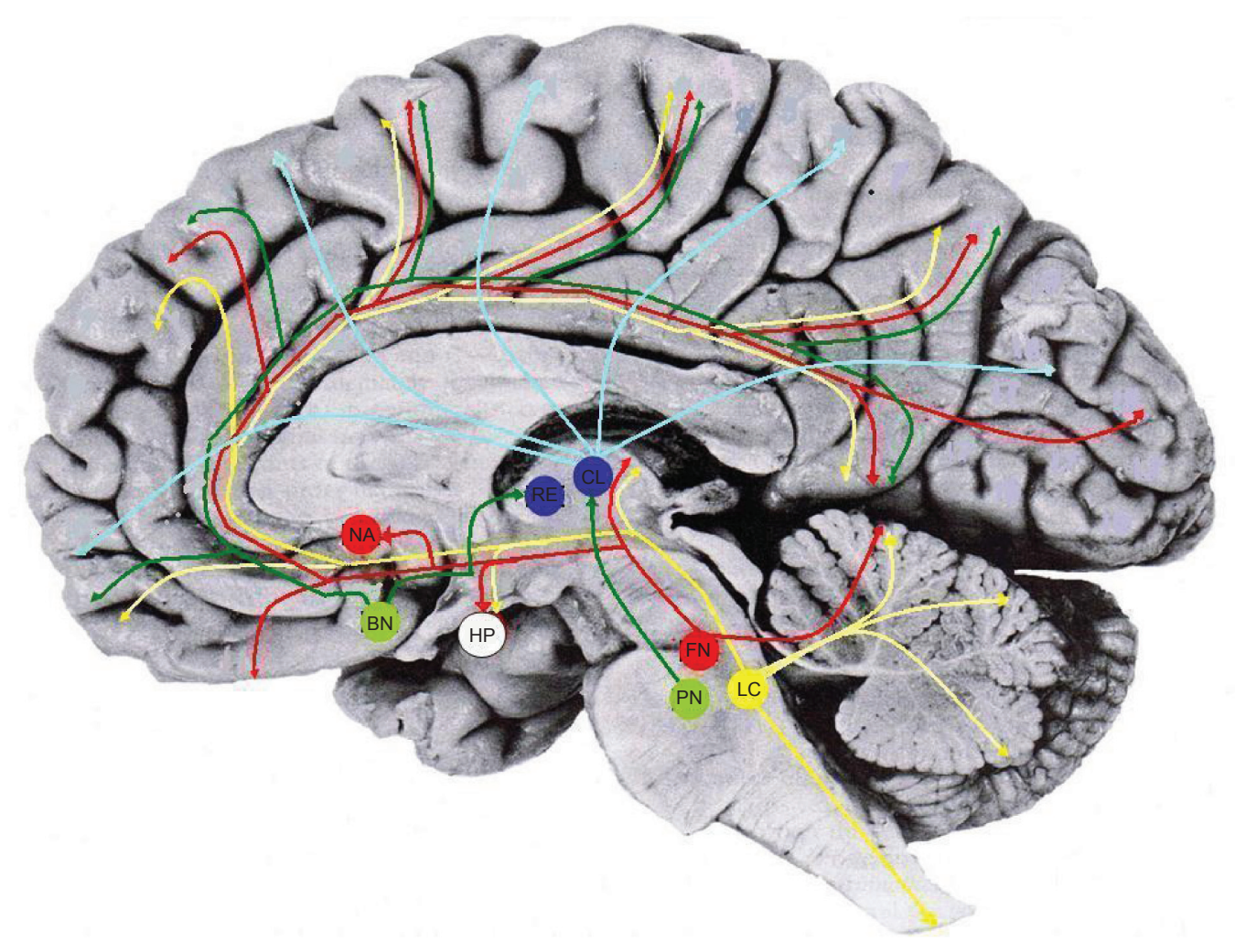

Figure I The reticular activating system. Yellow, red, and green denote elements of the noradrenergic, serotinergic and cholinergic pathways; respectively. Dark blue denotes modulatory glutaminergic thalamic nuclei.

Notes: Notice the close connectivity of the RAS with specific nuclei of the thalamus as well as with basal parts of the forebrain. Hence, Luria's notion of a tight link between the reticular activating system and the reciprocally connected prefrontal cortex is evident.

Abbreviations: CL, centrolateral nucleus of the thalamus; RE, reticular thalamic nucleus; HP, hypothalamus; LC, locus coeruleus; FN, raphe nucleus; PN, pedunculopontine nucleus; BN, basal nucleus of meynert; NA, nucleus accumbens. 
are effective in inducing and maintaining the enhanced excitability of neurons in higher cortical structures ${ }^{49}$ and are important in modulating signal-noise ratios of thalamocortical projections. Thus cholinergic innervation of the thalamus is provided by the brainstem whereas cholinergic innervation of the cortex is provided by the basal forebrain.

The serotonergic (5HT) projections of the raphe nucleus (FN) project to a large number of forebrain structures such as the nucleus accumbens (NA) depicted in red in Figure 1. Also the 5HT projections innervate the hypothalamus along the way to projecting throughout the cerebral cortex via the cingulum. Noradrenergic projections originating in the locus coeruleus (LC) of the rostrolateral pons course through many areas including the forebrain, cerebellum, spinal cord, and cerebral cortex. The noradrenergic fibers also innervate the hypothalamus on the way to the cerebral cortex and these projections are depicted in yellow in Figure $1 .{ }^{50}$ Both the serotonergic raphe nucleus and adrenergic locus coeruleus innervate and modulate the hypothalamus (HP) depicted in white on their way to the cerebral cortex.

It is important to mention that the brainstem reticular formation innervates by means of ascending and descending axons many regions of the CNS; although ascending tracts are mainly depicted in Figure 1. Differentiation in terms of functions of the RAS occurs through the actions of four main types of neurotransmitter codes: (i) acetylcholine (green), (ii) serotoninergic (red), (iii) adrenergic (yellow), and (iv) glutaminergic (light blue) projections. Recently it has been demonstrated that both thalamocortical and corticothalamic glutaminergic neurons use metabotropic long-term activation synapses which mediate prolonged excitatory actions similar to that induced by acetylcholine. Finally from a functional perspective only cholinergic and glutaminergic projections are activated during both arousal and rapid eye movement (REM) sleep whereas noradrenergic and serotonergic receptors are only activated during arousal. ${ }^{48}$

During the natural states of vigilance commonly encountered during simple neuropsychological attention or arousal all of these transmitters are released, however the interaction of these dynamic systems on the activity of the thalamus and cortex together are not yet fully understood. It seems then that Luria's notion of an arousal-attention unit is highly relevant if we elaborate his monolithic nonspecific view of the RAS into a distributed and multiple-action site of neurotransmitter functions. A final difference between Luria's model of an arousalattention unit ${ }^{6}$ and current models ${ }^{48}$ is a recognition that there are series of activating and arousing subsystems and cascades beginning within the brainstem, pontine, rostral mesencephalic nuclei and finally cresting in specific neuromodulatory thalamic nuclei complexes. This revised model of Luria's is quite concordant with other neuropsychological theorists of brainstem sensory and thalamic attention and tonic arousal. ${ }^{51}$

\section{The two coding units and contemporary views}

The first natural philosophical description of the precursors of simultaneous and successive cognitive processes were characterized by the Russian physiologist Ivan Sechenov in $1891^{52}$ and then only subsequently elaborated and further articulated more fully by Luria. ${ }^{53}$ Luria arrived at the conclusion that these two cognitive processes exist in human information processing through the systematic assessment of hundreds of brain-injured patients. Contemporarily these processes can be best conceived of as functional neural pathways or neurocomputational systems with some degree of invariant core structures such that representations can be elaborated and built upon to increase the complexity and flexibility of the organism's behavior and knowledge-base.

Luria and Artem'eva did not disparage factor analysis, rather they viewed it as a technique for categorizing and classifying the mass of secondary symptoms accruing from a primary localized brain injury. ${ }^{54}$ Using syndrome analysis and the comparison of symptomological profiles resulted in the eduction of dual primary 'higher-order' processes common across sensory modalities, types of tasks, subjects, and varieties of brain lesions. Such higher-order processes by which information is registered, encoded, elaborated upon, stored and finally integrated with the individual's extant knowledge base then corresponds to core cognitive systems associated with specific functional neuroanatomical systems. In contrast, Das and colleagues primarily used factor analysis and task decomposition ${ }^{15}$ to identify statistically simultaneous and successive processes and then conducted systematic studies cross-culturally and across demographic variables in order to verify the existence of these hypothesized processes.

Although Luria acknowledged that perceptual and mnestic forms of these two processes could be found, it is the latter memory encoding functions that are most closely associated with Das, Kirby, and Jarman's theory of simultaneous and successive cognitive processes..$^{15}$ It is important to note that simultaneous and successive are not synonymous with nonverbal and verbal processing; respectively. As an example, it is possible that visual information can be processed successively; ${ }^{55}$ and auditory information can be processed simultaneously as in sound localization. ${ }^{56}$ Luria notes that the second functional unit is important " ...for obtaining, processing and storing 
information arriving from the outside world..." (p. 43) and thus is essentially a coding component. ${ }^{14}$

In their review of the significance of Luria's work in its entirety, Stuss and Benson ${ }^{57}$ note that

...Posterior (parietal-occipital) brain regions are important in the simultaneous synthesis of incoming information; damage in these areas leads to particular syndromes, including deficits in decoding phonetic elements and in grasping logical, grammatical relations in language. Anterior cortex, on the other hand, including both frontal and frontal-temporal zones [anterior temporal opercular regions in particular], is relevant in the synthesis of successive elements into a single continuous sequential series. Disturbances of "successive synthesis" may be observed in the reproduction of rhythms, movements, words or numbers, and series of actions. Anterior brain damage may cause deterioration in the smooth flow from subject to verb. Luria described this as a failure in syntagmatic organization, a deficit of internal speech, eventually resulting in a telegraphic style... (p. 31).

The distinction between two orthogonal yet mutually interacting types of encoding processes is not without precedence in cognitive psychology. Broadbent's initial description of filter theory distinguished between early parallel and then only later subsequent serial processing. ${ }^{58}$ Treisman's widely accepted feature integration theory is a reformulation of Broadbent's original theory in which there is similarly parallel-then-serial feedforward architecture but proposing a major role for the inferior parietal lobe in the spatial integration of features at selected locations. ${ }^{59}$ Therefore these two processes are primarily responsible for the encoding, storage, as well as the transitory representation of information. In the example of seriation, each item is linked to the next in succession, or, in the case of simultaneous processing each item in a related gestalt is surveyable from any vantage point. These concepts are analogous to analytic and holistic processing, respectively of Peterson and Rhodes. ${ }^{60}$ In this sense simultaneous and successive processing constitute the two major modes of information integration in cognitive functioning. Table 1 describes in more detail tasks in different modalities, means of input and output that have been demonstrated to tap simultaneous and successive processing through factor analysis across ability, age, cultural, and socioeconomic groupings.

\section{Similar dual processing dichotomies}

A generalized dual dichotomy of cognitive processes is not without precedence in cognitive neuropsychology. There are at least half-a-dozen well articulated cognitive process
Table I Simultaneous and successive cognitive processes. Adapted and redrawn from Das, Kirby, and Jarman ${ }^{15,19}$

Simultaneous tasks

I. Syllogisms: Huttenlocher and Higgins ${ }^{6}$

2. Similarities:Wechsler ${ }^{62}$

3. Paired associate; Concrete words: Paivio ${ }^{63}$

4. Paper folding: French, Ekstrom, and Price ${ }^{64}$

5. Figure copying: Benton ${ }^{65}$

6. Memory for designs: Graham and Kendall ${ }^{66}$

7. Matrices: Raven ${ }^{67}$

8. Visual short-term memory: Sperling ${ }^{68}$

9. Cross-modal coding (audiovisual synaesthesia): Birch and Belmont ${ }^{69}$

Successive tasks

I. Digit span:Wechsler ${ }^{62}$

2. Paired associate abstract (verbal mediation): Paivio $^{63}$

3. Memory span - Concrete words (written): Paivio and colleagues ${ }^{70}$

4. Memory span -Abstract words (written): Paivio and colleagues ${ }^{70}$

5. Auditory serial recall (semantic versus phonological similarity): Paivio and colleagues ${ }^{70}$

6. Auditory free recall (semantic versus phonological similarity): Paivio and colleagues ${ }^{70}$

dichotomies that bear some theoretical resemblances to the simultaneous and successive dichotomy. ${ }^{15}$ Imagery and verbal processes or synchronic thinking is the first and perhaps most closely related set of concepts to the simultaneous successive model. ${ }^{71}$ Paivio's model can be seen as a verbal-nonverbal distinction that is based on the two hemispheres of the brain; whereas Das and colleague's model recognizes that there can be verbal simultaneous tasks as well as nonverbal successive tasks and may associated with a rostral-posterior designation of function in addition to laterality distinctions.

Paradigmatic and syntagmatic dual functions have traditionally been associated with the study of different types of aphasia in the context of developmental psychological theory. ${ }^{72}$ Paradigmatic organization of language is then associated with simultaneous processing or classification of words within a certain category; whereas syntagmatic organization (successive) is the joining together of words into a coherent expression. ${ }^{73}$ These two functions of paradigmatic and syntagmatic functions were associated with the posterior and anterior zone(s); respectively of the dominant hemisphere. ${ }^{74}$

Serial and parallel processes are typical of visual search tasks and share some characteristics with the successive and simultaneous processes; respectively. Parallel processes have been conceived of as "pre-attentive" in that the entire search array is processed simultaneously. This type of pre-attentive 
search demonstrates the pop-out effect such that reaction times are not influenced by the number of distracters in the array. ${ }^{75,76}$ Moreover, such pre-attentive or parallel processes are manifestations of maps of individual features that are characteristically associated with bilateral low-level visual cortex. In contrast, serial processes are associated with "attention-requiring" processes such that reaction times are linearly related with array size. These serial processes are defined by the conglomeration of two or more features or conjunctions which are detected as integration at the level of the "master map of locations" and rely on the integrity of the parietal lobes. ${ }^{75,76}$

Another popular distinction has been between holistic and analytic processes corresponding to simultaneous and successive processes; respectively. ${ }^{60}$ Holistic processes are configural in the sense that these are spatial-relational processes, however these entities do not denote a spatial feature per se, rather these processes refer to integrated information regarding components. In contrast, analytic processes are componential and part-based with a finer grain of resolution. Behrmann and colleagues's study of an integrative agnosic might be illustrative of key differences between simultaneous and successive processes, their possible neural correlates, and principles of the functional organization of related dual processing concepts. ${ }^{77}$

As Behrmann notes: “...Patient CK produces a reasonably good rendition of targets consisting of black and white geometric figures... However, he does so in an unusal way: the numbers assigned to the different strokes indicate the order in which the lines were drawn. Instead of deriving the holistic percept of two diamonds and a circle as unimpaired subjects might do, CK copies the individual lines slavishly and segmentally, without appearing to appreciate the identities." (p. 301-302). ${ }^{78}$ This segmental approach to copying gestalt items is characteristic of other integrative agnosics. ${ }^{79}$ Behrmann further elaborates how integrative agnosics characteristically are disproportionately impaired on holistic or configural tasks as well as figure-ground segregation, visual interpolation, and grouping. ${ }^{78}$ Finally, in five out of seven reviewed cases of integrative agnosia, Behrmann found deficits in holistic processes in all subjects as well as common lesions within the right posterior cortex. ${ }^{78}$ Collectively, these findings suggest that, in Figure 2, CK may be using intact successive coding to map out the target gestalt figure since simultaneous processing might be expected to be disrupted given the common loci of integrative agnosic's lesions.

Finally the fifth discernable dichotomy with relevance to simultaneous and successive processes is that between global and local processes; respectively. Initial studies using subjects with lesions of the left and right temporoparietal junction found loss of local and global elements of Navon figures; respectively. ${ }^{80,81}$ Subsequent studies using the Rey-Osterreith complex figure found that the global configuration was missing with right hemisphere damage and that the converse loss of local elements was found with left hemisphere damage. ${ }^{82}$ Similarly, a plethora of recent functional neuroimaging studies have found that the right temporal-parietal and left posterior temporal regions were differentially activated during attentional allocation to the global and local levels, respectively. ${ }^{83,84}$ With a review of Luria's and Das's theoretical conception of these two coding units and related dual processing dichotomies complete we can now turn to studies demonstrating the neural correlates of these two cognitive processes.

\section{Simultaneous processing: Neural correlates}

Simultaneous processing involves the arrangement of incoming information into a holistic pattern or gestalt that can be surveyed at once in its entirety. Sight recognition of whole words rather than identification of the individual letters is provided as an excellent case in point of such mnestic processing. ${ }^{3}$ Geometrical, topological math problems, or verbal spatial relationships in language may similarly require that one hold all the elements in mind in order to survey the fragments before solving a problem. Afferent synthesis of informational fragments into quasi-stable perceptual units occurs in simultaneous processing such that separate elements are integrated into groups with these arrays taking on spatial overtones. However, these representations are by no means exclusively visuospatial in character. ${ }^{19}$ The essential nature of this sort of processing is that any portion of the intermediary representation is at once surveyable without any dependence upon its position in the whole and thus the representation has what would be best described mathematically as a topological rather than visuospatial character.

Lesions of the occipitoparietal regions causing defects in simultaneous syntheses and disturbances of spatial and gestalt perception are archetypal of this type of disorder. In 1909 Rezo Balint first described the features of this syndrome (now bearing his name), and it consists of optic ataxia, ocular apraxia and simultanagnosia, which usually occurred in its purest forms after bilateral occipitoparietal lesions. ${ }^{85}$ Luria's comprehensive analysis of simultanagnosia demonstrated that key features of the syndrome which are the restriction of perception to a single object or configuration such that the 


\section{Target model drawing}

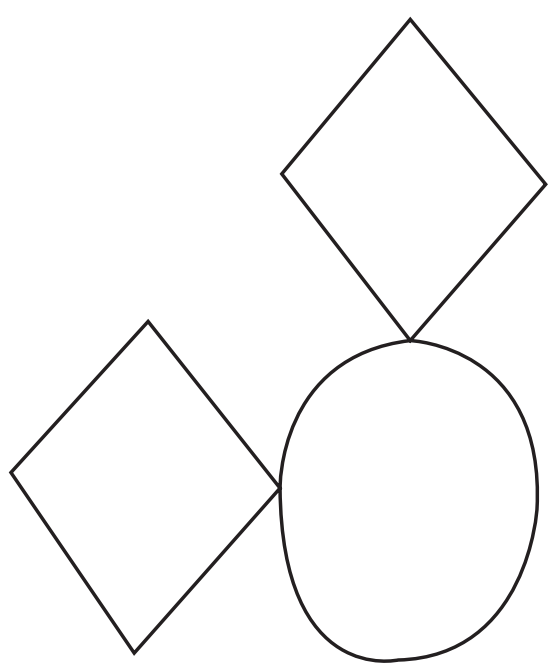

\section{CK's copy}

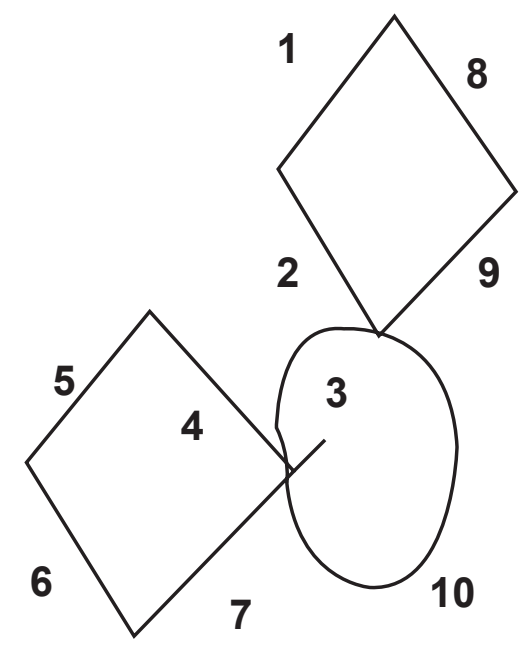

Figure 2 Hypothesized successive compensation of simultaneous processing deficiency in an integrative agnosic. Copy of the target (left) by CK with the numbers indicating the order of the strokes. Note that gestalt circles and square constructions are patently absent. Adapted and redrawn with permission Nature Publishing Group. From Behrmann M. Neuropsychological approaches to perceptual organization: Evidence from visual agnosia. In: Peterson MA, Rhodes G, editors. Perception of faces, objects and scenes:Analytic and holistic processes. New York, NY: Oxford University Press; 2003. p. 295-334.

affected patient is likely to perceive only a restricted element or aspect of the total stimulus pattern. ${ }^{86}$ Luria alluded to the fact that ideational or conceptual aspects of this disorder were not well-characterized or understood yet at that time. Luria and colleagues subsequently studied several other patients with characteristic bilateral occipitoparietal lesions and simultanagnosia and found that these patients demonstrated "piecemeal perception" such that integration of the gestalt story-line of a richly defined picture was abnormal. ${ }^{87}$

In a seminal study Coslett and Saffran studied these secondary cognitive aspects of simultanagnosia in more detail and found evidence that neither visual field reductions, nor, an incapacity to process visual features could account for the disorder ${ }^{88}$ Their simultanagnosic patient could easily identify briefly presented single words and objects as rapidly and reliably as control subjects suggesting that access to stored structural description of objects per se was not impaired. Interestingly, with the simultaneous presentation of two words or drawings the patient was able to identify both stimuli significantly more frequently when the stimuli were semantically related than when they were unrelated. These results suggest that simultanagnosia is fundamentally attributable to impairment whereby activated and intact structural descriptions of objects are linked through faulty informational coding as to the identity of an object. Hence the defective binding of semantic information with the structural description of an object figures prominently in the symptomatology of simultaneous agnosia.

Aysto and Hanninen demonstrated that a simultaneous verbal factor was highly sensitive to left hemisphere more than right-hemisphere lesions..$^{89} \mathrm{~A}$ difference in performance in favor of the right posterior lesions as opposed to left posterior lesions was marginally significant for this simultaneous verbal factor. Finally, a nonverbal simultaneous factor was also isolated through a factor analysis and patients with right posterior lesions were more impaired compared to those with left anterior lesions; a trend which reached marginal significance. Recent reviews of simultaneous agnosia all point towards the bilateral occipitoparietal regions as being critically involved. ${ }^{90}$

\section{Successive processing: Neural correlates}

Luria notes that patients with "lesions of the left temporal region...experiences considerable difficulty... when [they] attempt to carry out systematic, successive operations with 
relationships requiring the constant participation of speech associations as mediators..." (p. 121). ${ }^{6}$ Such processes include difficulties: (i) sequencing a series of pictures for a story by numbers instead of using proprioceptive and kinaesthetic imbued pointing; (ii) understanding a series of geometrical operations; (iii) step-wise mental arithmetical operations; (iv) logical problems through loss of access to word meanings, values, traces and well-established linguistic sequences; or (v) impairments in syntagmatic relationships as opposed paradigmatic relationships. ${ }^{74}$

Testing of the limits demonstrated that such lesioned patients could successfully perform successive tasks with the aid of visual depictions which Luria ${ }^{6,7}$ attributes to the substitution of degraded verbal memory traces with simultaneous processes. This is a seemingly reverse simultaneous-successive encoding compensation scenario as compared with the integrative agnosic patient CK (see Figure 2). A critical and early distinction that Luria made was between the "communication of events" and the "communications of relations" corresponding to essentially successive and simultaneous cognitive processes, respectively. ${ }^{91 a}$ This corresponds to the distinction between syntagmatic (syntactical constructions of temporal-ordering) analogous to successive processes versus paradigmatic or categorization-based relationships pertaining to hierarchies of concepts analogous to simultaneous processes. ${ }^{72,74}$

Successive then corresponds to temporal ordering of elements to be processed one by one and the whole sequence is not surveyable at any one time. ${ }^{15,19}$ Aysto and Hanninen note that in successive processing the information components are not necessarily related to each other in any systematic way, but may acquire meaning as a result of understanding the whole sequence and subsequent chunking. ${ }^{89}$ Thus a correlation or a direct association between stimuli is not required at the level of central processing; although once a linguistic or nonverbal sequence has been chunked in longterm memory this may well occur. Aysto and Hanninen used Das and colleagues's ${ }^{15,19}$ taxonomy of tasks to factor analyze

\footnotetext{
'Interestingly, as an aside, Luria's major contributions to aphasiology and problem solving in particular were undoubtedly significantly aided by the infrastructure associated with comprehensively assessing over 800 WWII Soviet soldiers. ${ }^{91}$ These individuals had been highly selected, comprehensively assessed in-depth neuropsychologically, and had sustained highly focalized 'clean' low-velocity high-calibre gunshot wounds. Such wounds are characteristically even more potentially focalized than occurs naturally in cases of ischemic and hemorrhagic stroke or traumatic brain injuries. ${ }^{10}$ Lezak notes that neuropsychologists who have had the opportunity to study such highly focalized wounds that occur virtually everywhere within the cortex have made, and will likely continue to make, major contributions to clinical and experimental neuropsychology as well as neuropsychological theory ${ }^{10}$ (eg, see also Luria $\left.{ }^{92}\right)$.
}

an eclectic collection of tests including some from the WAIS, Wechsler Memory Scales, and Benton Visual Retention Test using factor loadings as criterion.

According to Das, Kirby, and Jarman, once material is merged with long-term memory, subjects no longer engage in successive synthesis but characteristically implement a strategic difference in actual performance. ${ }^{15}$ The latter finding is entirely compatible with many functional neuroimaging studies of basal ganglia and cerebellar systems that are robustly activated when subjects engaged in strategic verbal or nonverbal processes that require the implementation of highly routinized sequences. ${ }^{93,94}$

Kim and colleagues found that verbal sequencing abilities were impaired by left hemisphere lesions whereas nonverbal sequencing tests were impaired by right hemisphere lesions. ${ }^{95}$ In a large adult sample of brain-injured patients Aysto and Hanninen found that left hemisphere-lesioned patients were significantly more impaired than the right hemisphere counterparts on successive processing. ${ }^{89}$ Similarly, a trend for regional specificity was also found such that the levels of performance of left posterior patients was less than that of left anterior patients, that these were less than that of right anterior patients, and finally that these were all less than that of right posterior patients.

These authors also noted that female subjects slightly outperformed their male counterparts on successive processing; a finding that was previously noted in reviews of simultaneous and successive cognitive processes. ${ }^{1,2,15}$ These lesion studies of the neural correlates of simultaneous and successive processes are for the most concordant with Luria's view of the neural specificity of these cognitive processes. However, the best test for the functional system supporting simultaneous and successive processes would not be a lesion study but rather functional neuroimaging studies. It is to such recent functional magnetic resonance imaging (fMRI) and electroencephalography (EEG) coherence studies of simultaneous and successive processes that we now examine. These functional neuroimaging studies

Table 2 Cognitive processes similar conceptually to simultaneous and successive

\begin{tabular}{lll}
\hline Simultaneous & Successive & References \\
\hline Imagery & Synchronic thinking & Paivio $^{71}$ \\
Paradigmatic & Syntagmatic & Jakobson $^{72}$ \\
Parallel & Serial & Treisman $^{76}$ \\
Holistic & Analytic & Peterson and Rhodes \\
Global & Local & Navon $^{80}$ \\
Coordinate & Categorical & Kosslyn $^{130}$ \\
\hline
\end{tabular}


might be expected to be superior to focal cortical lesion studies of stroke patients (despite the latter's methodological strengths), since in the former functional and effective connectivity rather than lesion localization can be established.

\section{Functional neuroimaging of simultaneous and successive processes}

Recently Okuhata, Okazaki and Maekawa examined EEG coherence patterns during simultaneous and successive processing tasks. ${ }^{96,97}$ The tasks from simultaneous and successive were retrofitted for use in an online computer-based delivery system (Stim System; Neuroscan Inc., Charlotte, $\mathrm{NC}, \mathrm{USA}$ ). EEG coherence can be described as the degree of similarity of the frequencies between two brain regions and it indexes the degree of functional cooperation and connectivity. EEG coherence is good means of assessing information processing mechanisms involving short and long range connections within the cortex. ${ }^{98}$ Such correlation within a frequency band can be interpreted as a functional measure for information transfer between brain regions and is analogous with functional neuroanatomical systems approach used in contemporary neuropsychiatry ${ }^{99}$ or a Luria-based syndromic approach used in cognitive neuropsychology. ${ }^{6,7}$

Okahuta and colleagues compared two CAS tasks that show the highest factor loadings with their respective simultaneous and successive composite factors scores. ${ }^{96}$ Figure memory loaded 0.68 on simultaneous and word series 0.72 on the successive factor. ${ }^{1}$ The results showed that there was an (i) indistinctive difference for the single simultaneous task in terms of coherence patterns; and a (ii) significant change in coherence between the bilateral frontal and left temporal regions in the beta frequency $(12-25 \mathrm{~Hz})$ for the successive task. Beta coherence has usually been considered to indicate higher cognitive processes especially of a verbal nature. ${ }^{100}$ (iii) Moreover there was no clear left-right asymmetry for verbal and nonverbal dimensions of the two tasks perhaps negating the left-right brain hypothesis often confused with the simultaneous-successive processing dichotomy. ${ }^{101}$ However, Okahuta and colleagues noted that the differential pattern could be due to a genuine difference in processing type or merely be a taskspecific (eg, nonverbal vs. verbal) since only one of each type of task was incorporated in the initial design. ${ }^{96}$

Therefore a second study was designed incorporating comparisons among multiple CAS subtests comprising each simultaneous and successive composite scale scores. ${ }^{97}$ Nonverbal matrices, verbal spatial relations, and figure memory were used for the simultaneous factor and word series, sentence repetition, and sentence questions were used for the successive factor. The tasks varied in task content (verbal or nonverbal) and modality (auditory or visual) and specific theta coherence patterns were observed irrespective of task content or modality. Simultaneous processing was characterized by increase short-range interhemispheric connections (eg, dual parietal activation) over central and parietal regions compared to successive processing (see Figure 3 ). This finding is congruent with theta selective responding to encoding of new information ${ }^{102}$ and with a previous study showing no impact of modality difference in the stimulus. ${ }^{103}$ Moreover, theta oscillations between 4-6 Hz are specifically related to working memory processes. ${ }^{104}$ Again, a significant methodological and interpretation difficulty with the results is that the DN-CAS contains no nonverbal successive tasks. However, previous functional neuroimaging studies using nonverbal sequencing tasks similar to those included on the successive processing scale may be able to help resolve this issue.

Control for sequential nonverbal movements has been found to require activation in the ventral portion of the lateral premotor cortex ${ }^{105}$ and the supplementary motor area. ${ }^{106}$ Bhimani and colleagues used $\mathrm{fMRI}^{107}$ to examine the anatomic organization the three Luria motor tasks of hand imitation, fist-edge-palm (FEP), and piano key (PK). ${ }^{6}$ All of these tasks are nonverbal and hand imitation does not involve sequencing since subjects only imitate from a target image. In contrast FEP and PK involved a greater degree of movement pacing and sequencing. Supplementary motor area was more active in FEP which is the task with the greatest degree of sequencing. Also parietal activation was found for all tasks due to the proprioceptive nature of the tasks performed without vision and all activation was found to be predominately within the right hemisphere. Poldrack and Willingham note that premotor, posterior parietal, and right hemisphere Broca's area homolog is most often implicated in such explicit sequence learning tasks and this type of neural network is most similar to the spatial working memory network. ${ }^{94}$

This right frontoparietal network involved in nonverbal sequencing suggests dual verbal and nonverbal sequencing or successive pathways in contrast to Luria's single frontotemporal pathway usually only referred to in the left hemisphere. ${ }^{6,7}$ A possible resolution of this inconsistency is that different configurations of dorsal and ventral pathways could be dominant within and across the hemispheres. ${ }^{83}$ Evidence from Balint's patients with bilateral occipitoparietal lesions is helpful in this regard. If spatial relationships 
between objects is processed by the dorsal stream while spatial relationships within objects is processed by the ventral stream then Balint's patient's intact ventral stream would be sufficient to represent the intrinsic spatial structure of an object. However the dorsal stream would be required to represent the spatial relationship between objects. Under these circumstances the ventral verbal sequencing stream would be expected to be dominant in the left hemisphere and the dorsal nonverbal sequencing stream might be expected to be dominant in the right hemisphere in almost all people. ${ }^{83}$ With a review of the theoretical and empirical foundations of the neuropsychological properties of the DN-CAS PASS scales complete we now turn to a discussion of a brief empirical study of this instrument in a small sample of well-characterized focal cortical lesion stroke patients.

\section{Method}

After neurology patients were admitted to the University of Alberta Hospital in Edmonton, Canada, patients who met inclusion-exclusion criteria were screened by a neurologist. The Director of Neurology was the coordinating and supervising physician and nurses or attending physicians screened subjects daily for inclusion into the study. At these physician's discretion subjects were recruited in a consecutive sample spanning nine months. After referral of such patients to the experimenter subjects were asked in-person for their written consent to participate in a study of cognitive functions following stroke or brain injury.

The median delay between stroke onset, acquisition of structural neuroimaging, and assessment with the CAS was approximately one month post-stroke. Case number 5 and case number 9 were outliers since these neurosurgical patients had surgeries for the excision of tumors with appended computed tomography (CT) scans that were approximately one year and six years old, respectively (Table 3). However, because these two patients' lesions were so circumscribed and well defined they were included in the study. In the remaining 31 subjects, the average time between peak stroke onset, intervening CT or MRI scanning and testing just before discharge with the DN-CAS was calculated ( mean $=27$ days $[\mathrm{SD} 22]$, range $=88$ days, minimum $=15$ days, and maximum $=88$ days). Under these circumstances most subjects were assessed while an in-patient at the stroke unit often just before their discharge from the hospital. Subjects completed the twelve subtests of the DN-CAS in either $1 \frac{1}{2}$ hour session with as many rest breaks between subtests as needed, or, alternatively on two separate 45 minute sessions on adjacent mornings in order to minimize fatigue and to ensure subjects were performing their best.

The inclusion criteria included those patients with: informed consent for participation and review of neurological charts; patients with localizable single ischemic or hemorrhagic stroke lesions; approximately equal distribution of lesions locations across the left and right frontal lobes (frontal lobes) and the left and right posterior cortices (temporal, occipital, parietal). The frontal lobe lesioned subjects included in the study had to have lesions with a center of mass and volume that was greater than or equal to $75 \%$ rostral to the central sulcus. The posterior lesioned patients included in the study had to have lesions with a center of mass and volume that were greater than or equal to $75 \%$ caudal to the central sulcus located primarily within either the parietal, occipital, and/or temporal lobes. The exclusionary criteria included those patients with: diffuse lesions, moderate to severe stroke, post-stroke depression, severe receptive aphasia, under the care of a guardian, extensive primary occipital cortex lesions and accompanying severe visual field defect, neurodegenerative disease or advanced age such that it would be difficult to distinguish whether normal aging or mild lesion's effects were the primary cause of the patient's cognitive dysfunctions (eg, advanced age $\sim \geq 70$ ).

Subjects with lesions of either left or right hemisphere but not both were recruited into the study in approximately equal proportions. A total of ten subjects with either negligible lesions (eg, subtle frontal atrophy) as determined by neuroradiological MRI or CT scan, or small cerebellar, midbrain lesions or cyst resections with no intrusion into gray or white matter were used as the control group subjects. Hence, these consisted of patients for which there was little evidence of focal cortical lesions or who had a patent subcortical lesion or alternatively a neurological patient without any visualizable surgically-induced loss of brain tissue (eg, external optic nerve cyst resection).

Subjects were administered Annett's 12-point questionnaire to evaluate handedness. ${ }^{109}$ At the same time that this preliminary assessment was completed demographic information was also gathered. Documentation regarding lesion locus, severity, lateralization, clinical neurological, radiological, and neuroradiological findings was collated under the supervision of participating neurologists. The sample control group consisted of 33 brain-lesioned patients of mean age 46 years $(\mathrm{SD}=13)$; male $=24$, female $=9$; mean educational level $=12$ years $(\mathrm{SD}=3)$; handedness: left $=8$, right $=25$. Ninety-one percent of subjects were Caucasian 
Table 3 Demographics of the DN-CAS focal cortical lesion study sample

\begin{tabular}{|c|c|c|c|c|c|c|c|}
\hline Case Lesion & Lat & $\mathbf{A} / \mathbf{P}$ & Sex & Age & Hand & Educ & Ethnic \\
\hline I Posterior left frontal lobe & Left & Ant. & M & 4 & Right & 4 & C \\
\hline $2 \mathrm{LT}$ frontal horn and LT basal ganglia & Left & Ant. & $\mathrm{F}$ & 3 & Left & 2 & C \\
\hline 3 Anterior left frontal lobe & Left & Ant. & $\mathrm{F}$ & 4 & Left & 2 & $\mathrm{C}$ \\
\hline 4 Left frontal lobe & Left & Ant. & M & 3 & Right & 2 & $\mathrm{C}$ \\
\hline 5 LT inf. frontal and cingulate gyrus & Left & Ant. & M & 5 & Right & 2 & C \\
\hline $6 \mathrm{LT}$ temporal lobe lesion & Left & Pos. & M & 3 & Right & 2 & C \\
\hline 7 Left temporal lobe & Left & Pos. & M & 3 & Right & 2 & $\mathrm{C}$ \\
\hline 8 Left occipitotemporal lesion & Left & Pos. & M & 4 & Right & 2 & $\mathrm{C}$ \\
\hline 9 Left parieto-occipital craniotomy & Left & Pos. & M & 5 & Right & 2 & C \\
\hline I0 LT parietal arteriovenous lesion & Left & Pos. & M & 2 & Right & I & $\mathrm{F}$ \\
\hline I I Left paracentral lobule & Left & Pos. & M & 2 & Right & 2 & $\mathrm{C}$ \\
\hline I2 RT posterior frontal operculum & Right & Ant. & $\mathrm{F}$ & 4 & Left & 2 & $\mathrm{C}$ \\
\hline I3 Right frontal lobe and basal ganglia & Right & Ant. & $\mathrm{F}$ & 5 & Left & 2 & $\mathrm{C}$ \\
\hline I4 Right frontal lobe lesion & Right & Ant. & M & 4 & Left & 3 & C \\
\hline I5 Right posterior frontal lobe & Right & Ant. & $\mathrm{F}$ & 3 & Right & 2 & B \\
\hline I6 RT frontal lobe and frontal operculum & Right & Ant. & M & 3 & Right & 2 & $\mathrm{C}$ \\
\hline I7 RT frontal lobe and RT basal ganglia & Right & Ant. & M & 4 & Right & 4 & C \\
\hline I8 RT frontal lobe and internal capsule & Right & Ant. & M & 4 & Right & 2 & C \\
\hline I9 RT c. semiovale and paracentral sulcus & Right & Pos. & M & 4 & Right & 3 & A \\
\hline 20 RT c. semiovale and paracentral sulcus & Right & Pos. & M & 2 & Right & 3 & $\mathrm{C}$ \\
\hline 2I Right frontoparietal lobe & Right & Pos. & M & 5 & Right & I & $\mathrm{C}$ \\
\hline 22 Right temporoparietal region & Right & Pos. & $\mathrm{F}$ & 3 & Right & 2 & C \\
\hline 23 Right frontoparietal region & Right & Pos. & M & 4 & Left & 2 & C \\
\hline 24 Bilateral frontal lobe lesions & $\mathrm{C}$ & C & M & I & Left & 2 & C \\
\hline 25 Left frontotemporal lobar tumor & C & C & $\mathrm{F}$ & 2 & Right & 4 & $\mathrm{C}$ \\
\hline 26 Bilateral frontal lobe atrophy & C & C & M & 3 & Right & 2 & C \\
\hline 27 Bilateral frontal lobe atrophy & C & $\mathrm{C}$ & $\mathrm{F}$ & 2 & Right & 2 & C \\
\hline 28 Bilateral medial frontal lesions & C & C & M & I & Right & 3 & $\mathrm{C}$ \\
\hline 29 Right cerebellar lesion & C & C & $\mathrm{F}$ & 2 & Right & 2 & C \\
\hline 30 RT posterior cerebellar hemisphere & C & C & M & 5 & Right & 2 & C \\
\hline 3I Superior right cerebellar hemisphere & C & C & M & 3 & Right & 2 & C \\
\hline 32 Postero-central midbrain-pons lesion & C & $\mathrm{C}$ & M & 4 & Right & 3 & C \\
\hline 33 Unspecified contusion & C & C & M & 1 & Right & 2 & C \\
\hline
\end{tabular}

Abbreviations: Ant, anterior lesion; Pos, posterior lesion; Lat, Laterality of lesion; c, centrum; C (Lat or A/P), control group; M, male; F, female; LT, left; RT, right; Hand, handedness; Educ, educational level in years of formal education (I: $\leq 8,2: 9-12,3: 13-I 4,4: \geq I 5$ years, respectively); Age (I: $\leq 25,2: 26-40,3: 4 I-50,4: 5 I-60,5: \geq 6 I$ years, respectively); Ethnic group (C, Caucasian; B, Black; A, Asian; F, First Nation).

$(\mathrm{N}=30) ; 3 \%$ of subjects were Black $(\mathrm{N}=1) ; 3 \%$ of subjects were Asian $(\mathrm{N}=1)$; and $3 \%$ of subjects were First Nations $(\mathrm{N}=1)$. Previous analysis demonstrated no significant differences in these demographic variables on subtest t-scores at the aggregate sample level. ${ }^{109}$

Since no adequate norms yet exist for the DN-CAS for adults with a mean age of 46 (age range $=20-67$ ) Russell's average z-score index was used. ${ }^{110}$ The average z-score method consists of four steps: (i) choosing a reference group of tests; (ii) combining the results from those tests into a reference scale; (iii) deriving scale scores from the reference scale using multiple regression; (iv) anchoring to some specific group with a known level of absolute performance on the task(s) in question. The anchoring population used in this study was 17 year-8-month-old US students derived from the DN-CAS standardization sample. Lezak notes that “...tests of mental ability that provide adult norms extending into the late teens find that the population of 18 year olds does not perform much differently than the adult population at large..." (p. 158). ${ }^{10}$ Moreover, Naglieri and Das's interpretive manual 


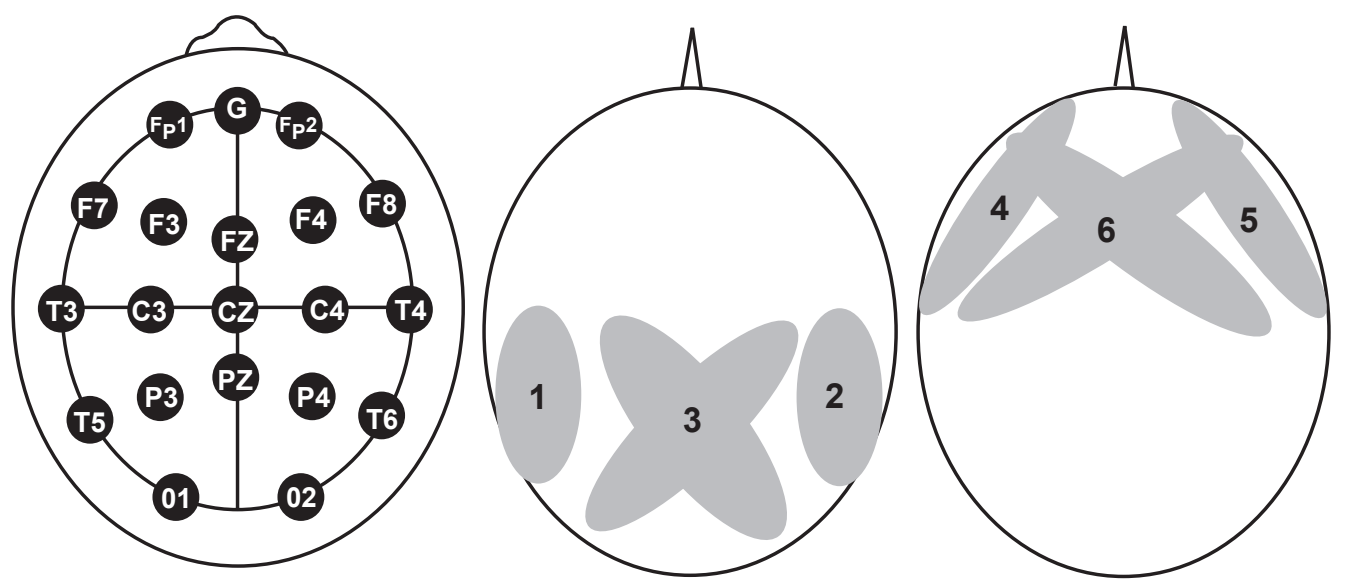

Figure 3 Hypothetical neural networks underlying simultaneous and successive cognitive processes. Top left: International I0-20 system for the placement of EEG electrodes. F, T, C, P, O, and Z refer to the frontal, temporal, central, parietal, and occipital lobes, respectively. Z refers to reference electrodes placed upon the midline. Top middle and right: Diagram of hypothetical electrode pairing coherence connections for simultaneous and successive cognitive processes. I, Simultaneous left (OI-C3, P3). 2, Simultaneous right (O2-C4, P4). 3, Simultaneous interhemispheric (OI-C4, P4; O2-C3, P3). 4, Successive left (T3, 5-F3, 7; FPI). 5, Successive right (T4, 6-F4, 8; FP2). 6, Successive interhemispheric (T3,T5 : F4, F8, FP2;T4,T6 : F3, F7, FPI).Adapted and redrawn with permission of Elsevier: Okuhata ST, Okazaki S, Maekawa H. Differential topographic pattern of EEG coherence between simultaneous and successive coding tasks. Int J Psychophysiol. 2007; 66:66-80.96

shows that across most of the CAS subtests there is near asymptotic levels of performance cresting near the age of 18 years. ${ }^{1}$ Similarly, Ryan and colleagues's study confirmed this assertion by finding that within a large sample of college students the CAS's subtests great range of difficulty of items was more than sufficient to objectively measure changes in cognitive functioning across subgroups without any floor or ceiling effects. ${ }^{26}$

Hence, brain-damaged patient's scores were normed using the average z-score index of impairment with the raw scores of the 18-year-old group in the DN-CAS standardization sample used as baseline. All the subject's index scores were averaged to form the reference scale. That is, using the z-scores, the 12 CAS subtests were summed and divided by 12 for each subject. In this way the average index of impairment was created with a mean of 1 and each interval was equivalent to a standard deviation unit. The scaled scores for individual CAS subtests and participants were derived through a series of 12 separate multiple regressions for each subtest. Average z-score indexes of impairment were regressed on to subtest raw scores yielding predicted raw scores with distributions that were equated across subtests. Therefore, a given level of impairment on one CAS subtest was equivalent to that on any another CAS subtest.

\section{Results}

Cluster analysis is the assignment of observations into groups such that observations in one cluster are more similar to each other compared to observations from different clusters. Cluster analysis is particularly useful in pattern recognition and hence single-case study design. ${ }^{111}$ Hierarchical clustering finds clusters by first using more basic level structures within a data set; while agglomerative algorithms are those that are bottom-up statistical processes that begin with each element as a separate cluster. Smaller clusters are then merged into successively larger clusters. Euclidean distance can be used to separate clusters and it is a symmetrical metric and is the most common distance measure used in psychology studies. Hierarchical agglomerative cluster analysis (as used in this particular study), traditionally utilizes a visualization format in which the classification of observations is represented in the form of a tree-like hierarchy or dendrogram (eg, Figure 4). In this representation individual elements or cases are depicted at one end and a single higher-order cluster containing every element is located at the other end of the dendrogram.

The 33 cases with 12 observations of subtest performance per subject constitutes approximately 400 singlet observations which is more than satisfactory for a hierarchical agglomerative cluster analysis (HACA). During HACA determination of the number of clusters involves: (i) visual inspection of the dendrograms; (ii) as well as observation of the largest single jump in the cluster coefficient according to the methods described by Aldenderfer and Blashfield. ${ }^{112}$ Figure 4 illustrates the point at which the dendrogram flattens out most and it shows that there are three unambiguous primary clusters. At least a dozen iterations using several of the most common (i) clustering methods as well as (ii) interval measures or metrics all converged on the same solution depicted in Figure 4. This method was most reproducible, stable, and meaningful using the common metrics of between-groups linkage and squared Euclidean distance. 


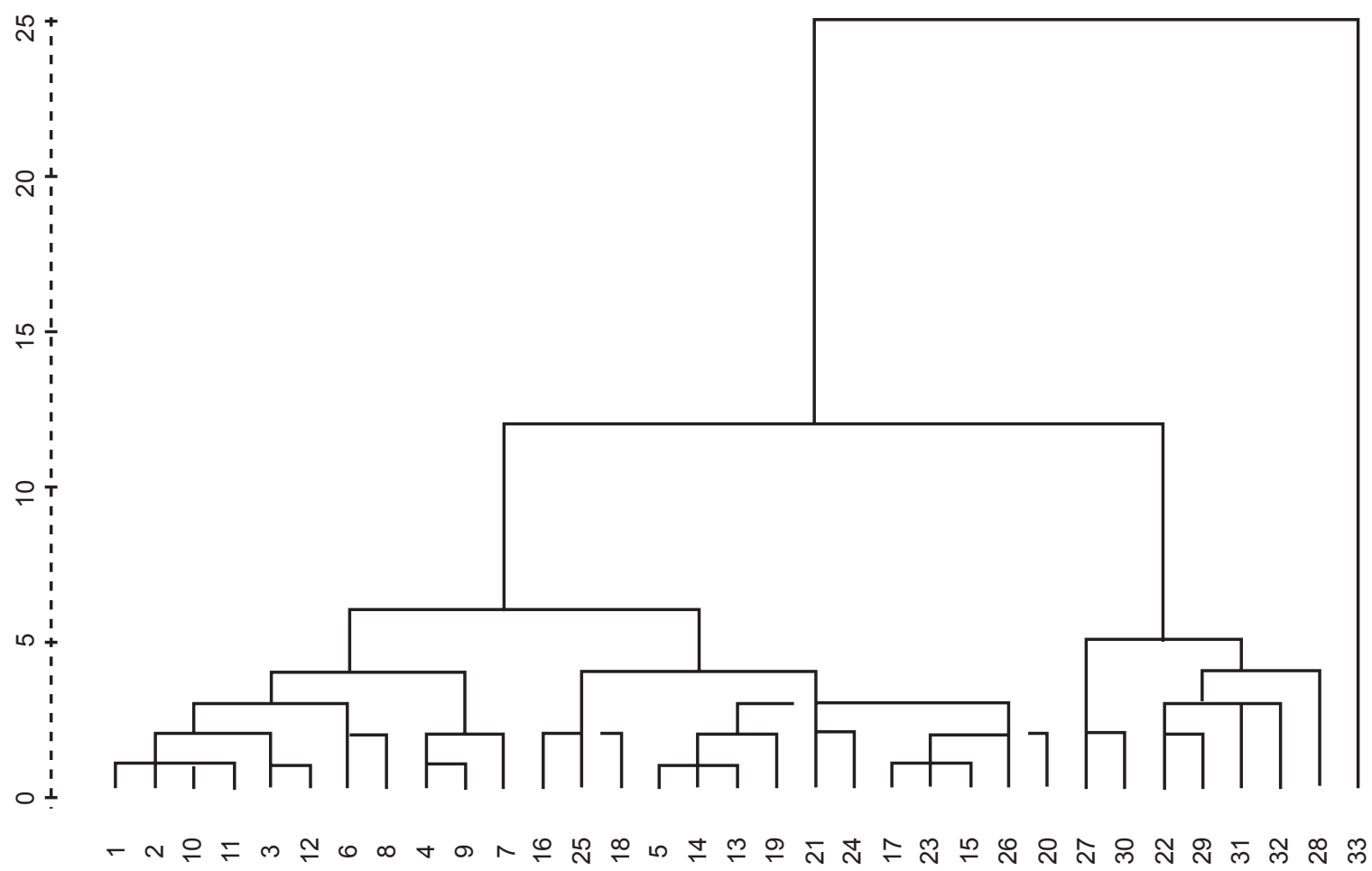

Figure 4 Dendrogram of the hierarchical agglomerative cluster analysis. The $y$-axis depicts the dendrogram cluster coefficients and the $x$-axis lists the case numbers depicted in Table 3.Thirty-three individual cases with twelve Das-Naglieri cognitive assessment system subtest scores per subject for a grand total of approximately 400 singlet observations. This number of observations provides more than enough variance between and across subjects for statistically reliable hierarchical agglomerative cluster analysis. ${ }^{1 / 2}$

This qualitative analysis was followed by confirmatory statistical inferencing using cross-tabulations of frequency distributions across the (1) rostral-caudal and (2) laterality axes (see Goldstein and colleagues for an identical type of analyses using the LNNB). ${ }^{12}$ Only one cluster solution is usually found for a particular data set of this size and it designates the intrinsic structure of observation co-variance and logical patterns. ${ }^{12}$ The cluster solution closely paralleled the configuration for laterality of lesions as opposed to the rostral-causal loci of the lesions. That is, most of the variance was explained by the laterality of the lesion that maximized the distance between subjects and across subtests scores. The left hemisphere, right hemisphere and control groups were highly significantly concordant with clusters 1, 2 and 3; respectively $(r=0.85, \mathrm{p}<0.0001)$, such that only 5 of 33 or $18 \%$ of observations did not fit exactly into the original laterality groupings. Subsequent procedures using predicted subtest scores with laterality as covariate demonstrated that the anterior-posterior grouping did not contribute any more meaningful variance and that therefore the first cluster solution was based exclusively on laterality.

That such unequivocal results were found with such a moderately sized sample attests to the well characterized recruitment and selection of only highly focalized cortical lesion patients through appropriate neurologist-screening and neuroradiological consultation. However, others, notably Russell, have shown that recruitment of small samples with good lesion characteristics (of greater than or equal to $\mathrm{N}=30$ ), are more than adequate to provide reliable first-approximations or estimates of the neuropsychological specificity of a new psychometric instrument. ${ }^{110}$ This is all the more evident when the collection of subtests has been well-normed as in the original DN-CAS standardization. ${ }^{1}$

Table 4 depicts the three factor cluster solution's frequency tabulations of sex, handedness, age, education and ethnicity. One way analysis of variance (ANOVA) across the parametric variables of age and education did not reveal any significant differences across clusters (age: $\mathrm{F}(2,32)=2.28$, $\mathrm{p}>0.15$; education: $\mathrm{F}(2,32)=0.06, \mathrm{p}=0.95)$.

A Chi-square analysis of the cluster solution along the variables of sex, handedness, and ethnicity was performed. There were no significant group differences across the three cluster groupings in terms of frequency distributions for sex $\left(\chi^{2}[2]=1, p=0.72\right)$; handedness $\left(\chi^{2}[2]=4, p>0.15\right)$ or ethnicity $\left(\chi^{2}[2]=5, p=0.57\right)$. ANOVA statistically corrected for four parametric comparisons demonstrated that for the laterality of the lesion (eg, left-hemisphere, righthemisphere and control subjects) there were significant main effects for planning and simultaneous. In each case the right 
Table 4 Cluster solution group, gender, handedness, age, education and ethnicity

\begin{tabular}{|c|c|c|c|c|c|c|c|c|c|c|c|c|}
\hline \multirow[t]{2}{*}{ Cluster } & \multirow[t]{2}{*}{$M$} & \multirow[t]{2}{*}{$\mathbf{F}$} & \multicolumn{2}{|c|}{ Handedness } & \multicolumn{2}{|l|}{ Age } & \multicolumn{2}{|c|}{ Education } & \multicolumn{4}{|c|}{ Ethnicity } \\
\hline & & & $\overline{\mathrm{LT}}$ & $\overline{\mathrm{RT}}$ & Mean & $\overline{S . D .}$ & Mean & $\overline{\text { S.D. }}$ & $\bar{C}$ & $A$ & $B$ & $\bar{F}$ \\
\hline 1 & 8 & 3 & 4 & 7 & 48 & 11 & 12 & 3 & 10 & - & - & $\mathrm{I}$ \\
\hline 2 & 11 & 3 & 4 & 10 & 50 & 12 & 12 & 3 & 12 & 1 & I & - \\
\hline 3 & 5 & 3 & - & 8 & 38 & 15 & II & 2 & 8 & - & - & - \\
\hline Total & 24 & 9 & 8 & 25 & 46 & 13 & 12 & 3 & 30 & I & I & I \\
\hline
\end{tabular}

Abbreviations: Sex: M, male; F, female; Ethnicity: A, Asian; B, Black; C, Caucasian; F, First Nations.

hemisphere lesioned groups performed significantly worse on the planning and simultaneous composite scales than their control comparisons groups (Table 6).

\section{Discussion}

The two functional neuroimaging studies of simultaneous and successive processing reviewed suggested that simultaneous processing involved dual bilateral occipitoparietal coordination and that successive processing did not involve as much interhemispheric coordination. ${ }^{96,97}$ This view is consonant with Luria's initial studies of cases of simultanagnosia ${ }^{86,87}$ that provided some of the impetus for his formulation and articulation of the concept of simultaneous processing. The functional neuroimaging studies are also congruent with extensive reviews and detailed single case studies of modern simultanagnosic patients using imaging and cognitive neuropsychological testing. ${ }^{90}$ All such studies implicate the centrality of the integrity of bilateral occipitoparietal regions for eliciting the classic symptoms of simultanagnosia and presumably also involved in simultaneous processing.

The focal cortical lesion study included with this review also indicated that simultaneous processing was a function of the integrity of the right hemisphere, and left-sided lesions did not result in appreciable impairment in simultaneous processing. The apparent contradiction between the two functional neuroimaging and lesion study could be explained by the fact that the left temporoparietal junction appears to be involved in filling in local detail while the right temporoparietal junction results in difficulties in the appreciation of the global aspects of a figure. ${ }^{81,83}$ On this view impairment of global processing due to right parietal lesions would be much more disruptive to the core neural network involved in simultaneous processing. Our review of the integrative agnosic patient CK showed that what might be occurring when global processing is adversely effected (and therefore presumably disrupting simultaneous processing), is that successive processing could compensate by slavishly and segmentally coding the elements of the complete configuration..$^{77,78}$ This hypothesis would also be congruent with the close relationship between global and local processing integration and simultanagnosia ${ }^{90}$ as well as the dominant role of the right intraparietal sulcus in switching between spatial reference frames (eg, local and global detail). ${ }^{113}$

Secondly, the two functional neuroimaging studies implicated the involvement of bilateral frontal and anterior left temporal regions in successive processing. ${ }^{96,97}$ These findings are congruent with the hypothesis that the hemispheres are capable of sequencing either verbally as in the word series task, or, nonverbally as in the hand movements task of the K-ABC, Self-Ordered Pointing, or Corsi Blocks. The evidence taken as a whole seems to be concordant with this dual processing hypothesis despite the fact that the DN-CAS does not have a nonverbal sequencing tasks included within the standardization battery. Aysto and Hanninen found that their successive factor was sensitive to left hemisphere lesions; however all their successive tasks were verbal.$^{89} \mathrm{Kim}$ and colleagues found that verbal and nonverbal sequencing were impaired by left and right hemisphere lesions, respectively. ${ }^{95}$ Collectively these findings suggest that successive or sequencing is not lateralizable in the frontal regions perhaps given the extensive genual and anterior commissure connectivity required developmentally in the ontogeny of many bimanual coordination tasks. ${ }^{114,115}$

Using structural MRI, Kluger and Heilman found that Luria's test of reciprocal coordination (which is a test of bimanual coordination), could be elicited with frontal mesial lesions alone encompassing the supplementary motor areas, but sparing the anterior cingulate or corpus callosum. ${ }^{116}$ Chunking of action sequences may not necessarily require content domain-specificity (eg, verbal vs. nonverbal) for integration in the prefrontal cortex. This is because the spatial and temporal sinusoidal topology associated with such action repertoires would be sufficient for cross-mapping purposes via prefrontal-basal ganglia reciprocal connectivity. ${ }^{93}$ However the data do suggest that in the posterior cortex (eg, anterior temporal regions) that verbal and nonverbal sequencing is 
Table $\mathbf{5}$ Hierarchical agglomerative cluster analysis by laterality frequency

\begin{tabular}{lllll}
\hline Cluster & Laterality & & Total \\
\cline { 2 - 4 } & Left hem & Right hem & Control & \\
\hline I & 10 & $\mathrm{I}$ & - & $\mathrm{II}$ \\
2 & $\mathrm{I}$ & 10 & 3 & 14 \\
3 & - & $\mathrm{I}$ & 7 & 8 \\
Total & $\mathrm{I}$ & 12 & 10 & 33 \\
\hline
\end{tabular}

highly lateralizable. This could mean that there are two points of diversion for Successive processing that both converge on the ventral premotor and prefrontal regions and their basal ganglia connectivity where verbal and nonverbal content codes are integrated into unitary amodal codes. In contrast, simultaneous processing could function more seamlessly as a consequence of the integrity of the bilateral posterior parietal regions and their splenial connections vis-à-vis the corpus callosum. ${ }^{117}$ This suggests an as yet unspecified triple fasciculi-based coordinated sets of pathway(s) with a more anterior-posterior loci of connectivity for successive processing within the frontotemporal regions and a more laterally expansive foci for simultaneous processing across the parietal lobes.

The composite factor of attention was not found to be localizable to any brain region and this fits with its extensive connectivity using at least four different neurotransmitter systems emanating from the reticulothalamic formation. However it is important to note that exclusively subcortical patients with large lesions were excluded from the study. The bulk of such connections course through the medial forebrain bundle and synapse with the basal ganglia, medial temporal lobe and the nucleus accumbens (Figure 1). As such the attention composite factor is tightly yoked to the functioning of the prefrontal cortex as originally articulated by Luria. ${ }^{6,7}$

Of unique interest is that the ventromedial aspect of the frontal lobe contains numerous autonomic nervous system nuclei and connections which regulate and modulate the reticular formation in functions such as sleep, waking, and tonic arousal. ${ }^{118}$ Hence, yoking should be expected to be especially close between planning and attention if the tasks could be parametrically varied for difficulty and if the respective subtests could be retrofitted for use in other functional neuroimaging studies. Finally the planning composite scale was highly sensitive to right hemisphere lesions congruent with many studies showing that planning tasks are generally sensitive to frontal lesions (Grafman for an extensive review $\left.{ }^{19}\right)$. Subsequent studies have shown that problems with an ill-structured nature (such as are present in the DN-CAS planning composite scale), are highly sensitive to right prefrontal cortex lesions, ${ }^{120}$ which is entirely consistent with the results of the focal cortical lesion patient study.

\section{Conclusions}

Seminal contributions to neuropsychology methods by Luria include: understanding localization of function, higher cortical functions, functional systems, the symptom-complex and syndrome analysis, qualitative analysis, use of specific errors patterns, single case study design and rehabilitation theory. ${ }^{35}$ The cognitive neuropsychological analysis of the single case is in accordance with Luria's original qualitative method of syndrome profiles. ${ }^{43,111}$ In an influential review, Robertson and colleagues noted that the single-case routinely allows for the generalization beyond the single-case about what is and what is not possible to deduce or infer about the general population's brain functioning. ${ }^{121}$ In fact, some advocates of the single-case would go far beyond this statement and suggest that the single patient is the essence of deducing the core functions of how the brain is actually organized in vivo from a functional point of view. ${ }^{6,7}$ An examination of the enormous empirical, methodological, and theoretical advances within the last decade about how the ultra-structural white matter tracts of brain differ extremely from subject to subject suggests that the stronger form of this position is gaining much wider credence among the cognitive neuroscience community (eg, see Catani and fftyche ${ }^{122}$ ).

In this sense then Das, Kirby, and Jarman's concept of basic cognitive processes (rather that stimulus-specific content), directly mediating intelligent behavior is perhaps surprisingly contemporary. ${ }^{15,19}$ From the perspective of functional neuroimaging and cutting-edge statistical techniques these major simultaneous-successive throughputs could be conceived as probabilistic functional maps about how various types of input are invariably processed. Goebel and colleagues have provided just such an excellent example using fine-grained time-resolved fMRI in conjunction with diffusion tensor imaging fiber tracking and Granger causality mapping. ${ }^{123}$ Granger causality is a technique for determining whether a time series is useful in forecasting another time series and therefore it can be used to determine causality interactions between functional systems in highly complex sets of variables such as are used in fMRI. These investigators' studies demonstrated how occipitoparietal regions invariantly communicate with both homologous regions of the contralateral hemisphere in addition to informational ventral frontotemporal pathways presumably 
Table 6 ANOVA of CAS PASS scale composite t-scores across the three factor cluster solution. Bold values indicate level of significance levels with Bonferroni correction for multiple comparisons at $\mathrm{p} \leq 0.05$

\begin{tabular}{llllll}
\hline $\begin{array}{l}\text { PASS } \\
\text { scales }\end{array}$ & $\begin{array}{l}\text { Cluster I } \\
\text { t-score (SD) }\end{array}$ & $\begin{array}{l}\text { Cluster } \mathbf{2} \\
\text { t-score (SD) }\end{array}$ & $\begin{array}{l}\text { Control } \\
\text { t-score (SD) }\end{array}$ & ANOVA & Effect size estimate \\
\hline Planning & $49(12)$ & $44(7)$ & $56(8)$ & $\mathrm{F}(2,30)=3.9$, & $\mathrm{P}=0.03,1.2 \sigma$ \\
Attention & $48(9)$ & $46(I)$ & $54(9)$ & $\mathrm{ns}$ & $\mathrm{ns}$ \\
Simultaneous & $50(8)$ & $45(6)$ & $58(12)$ & $\mathrm{F}(2,30)=5.5$, & $\mathrm{P}=0.009,1.3 \sigma$ \\
Successive & $46(10)$ & $48(8)$ & $54(11)$ & $\mathrm{ns}$ & $\mathrm{ns}$ \\
\hline
\end{tabular}

Abbreviations: ANOVA, analyses of variance; CAS, cognitive assessment system; PASS, Planning-Arousal/Attention-Simultaneous-Successive; SD, standard deviation.

involved in sequencing. These two throughput pathways or functional systems of the brain could possibly be mediated by cross-modality global-local attentional modulators located within the intraparietal sulci (particularly within the right hemisphere), that bridge the superior temporal sulcus and the occipitoparietal junction..$^{83}$

The dual hemispheric posterior inferior parietal system coordinated by the splenium of the corpus callosum would then correspond to the simultaneous unit. ${ }^{114}$ In contrast the frontotemporal operculum would constitute in essence two separate sequencing systems (one of which was for verbal and the other for nonverbal communicative purposes), with the anterior commissure and genu of the corpus callosum used in mneumonic integration of these two systems. ${ }^{115,121}$ In view of these modern findings and the results of this accompanying study essentially multisensory and distributed dual cognitive processing rather than unimodal sensory-specific content processors appears to be the rule rather than the exception.

In the CAS there are no nonverbal successive tasks although, as mentioned in the introduction, there are many examples of such tasks in use in common neuropsychological practice (eg, Self-Ordered Pointing and Corsi blocks). ${ }^{18}$ Moreover and perhaps more importantly within the K-ABC, the hand movements task reliably loads on the sequential factor rather than a nonverbal factor. ${ }^{16}$ In the CAS there is just one example of a verbal simultaneous subtest, that being the verbal-spatial relations. As an example Aysto and Hanninen found that their "simultaneous verbal" factor was sensitive to left-hemisphere lesions; however their designation of WAIS-R information as a simultaneous-loading variable was questionable. ${ }^{89}$ It is known that anomia can result from lesions from many regions of the brain. ${ }^{125}$ Anomia is present in many left hemisphere-injured patients and it rarely recovers completely and thus invariably patients will have difficulty in retrieving information of low lexical frequency. Therefore Aysto and Hanninen's choice of information as an archetypal simultaneous task is doubtful especially in the context of Das, Kirby, and Jarman's extensive cross-cultural and factor analytic designation of more suitable tasks. ${ }^{15}$

McCrea found that verbal-spatial relations was not sensitive to left hemisphere lesions but rather was instead sensitive to anterior lesions in either hemisphere. ${ }^{109}$ Thus there does indeed seem to be some good support for the assertion that verbal-spatial relations is not simply a verbal task nor does it seem likely that it is simply a "verbal simultaneous" task. Hence, the pivotal axiom of simultaneous-successive theory that "code content is independent of code type" as originally hypothesized by Das, Kirby, and Jarman ${ }^{15,19}$ is strongly supported by the data from this study and the results of the review. Indeed the three functional neuroimaging studies using Lurian tasks are generally concordant with the view that code content is independent of code type ${ }^{96,97,107}$ which was a key maxim of Das, Naglieri, and Kirby's introductory text. ${ }^{2}$

In view of these subsequent studies and the results of this review, McCrea's preliminary statement that code content is not independent of code type should be qualified and revised. ${ }^{126}$ Although this initial stroke cortical lesion study had suggested that the CAS subtests may be useful in neuropsychological practice, ${ }^{109,127}$ the usefulness of the PASS scales per se would be better tested by functional neuroimaging studies in conjunction with lesion studies. ${ }^{128,129}$ Hence, McCrea's stroke lesion study ${ }^{126}$ may not have all the requisite design features necessary by itself to adequately test the axiom of simultaneous-successive theory that code content is independent of code type., ${ }^{2,15}$

The CAS subtests and composite scales have thus been shown to be useful for understanding learning disabilities and the PASS model could be particularly useful for neuropsychological rehabilitation purposes. Specifically, this instrument might be useful as either a quick screening instrument in brain injury samples to be used at the bedside or in fields such as occupational theory, speech language therapy, physical therapy, and psychiatric nursing where 
Luria's theories permeate many graduate courses and clinical practices. Recruitment of small neurosurgical patient populations with focal cortical excisions as used in this sample could further establish the neural sensitivity and specificity of the composite scales and CAS subtests. Finally cognitive neuropsychological adaptation of CAS subtests for use in functional neuroimaging experiments and the correlation of such studies with rehabilitation outcome studies would also likely be especially useful.

\section{Acknowledgments}

A Social Sciences and Humanities Research Council of Canada (SSHRC) doctoral research grant \#752-2000-1344 awarded to SMM supported this project. This research was also supported in part by a National Sciences and Engineering Research Council of Canada (NSERC) post-doctoral fellowship grant \#241750 awarded to SMM. This project was approved by Section B of the Health Research Ethics Board of Capital Health of the University of Alberta Hospital and was conducted in accordance with the Declaration of Helsinki. The author is grateful to Ashfaq Shuaib, MD, FRCP, Director of the Division of Neurology; Thomas Snyder, Ph.D., C. Psych. (AB.) of Neuropsychology; and Robert Ashforth, MD, FRCP of Neuroradiology of the University of Alberta Hospital for assisting in patient screening, referral, and lesion characterizations. Recruitment of select patients with highly focalized lesions would not have been possible without these individuals. Mark Gierl, Ph.D. of the Center for Research in Measurement and Evaluation (CRAME) assisted with statistical analysis. Finally, special thanks are duly credited to JP Das, Ph.D. whose critical ideas and enthusiasm for this study enabled it to begun. This manuscript was presented as a poster at the XVI Annual Meeting of the American Neuropsychiatric Association in February of 2005 in Miami, Florida. The author reports no conflict of interest in this work.

\section{References}

1. Naglieri JA, Das JP. Das-Naglieri Cognitive Assessment System. Itasca, Il: Riverside Publishing; 1997.

2. Das JP, Naglieri JA, Kirby JR. Assessment of cognitive processes. Boston, MA: Allyn and Bacon; 1994.

3. Das JP. A neo-Lurian approach to assessment and remediation. Neuropsychol Rev. 1999;9:107-116.

4. Das JP. A better look at intelligence. Curr Dir Psychol Sci. 2002; 11:28-33.

5. Naglieri JA. Essentials of CAS assessment. New York, NY: John Wiley and Sons; 1999.

6. Luria AR. Higher cortical functions in man. New York, NY: Basic Books; 1966.

7. Luria AR. Higher cortical functions in man. 2nd ed. New York, NY: Basic Books; 1980.
8. Maekawa H, Nakayama K, Okazaki S. Japanese version of the Das-Naglieri Cognitive Assessment System: Interpretive handbook. Tokyo, Japan: Nihon Bunka Kagakusha; 2007.

9. Golden CJ, Purisch AD, Hammeke TA. The Luria-Nebraska neuropsychological battery: Forms I and II. Los Angeles, CA: Western Psychological Services; 1985.

10. Lezak MD. Neuropsychological Assessment. 3rd ed. New York, NY: Oxford University Press; 1995.

11. Spiers PA. Have they come to praise Luria or to bury him?: The LuriaNebraska Battery controversy. J Consult Clin Psychol. 1981;49:331-341.

12. Goldstein G, Shelly C, McCue M, Kane RL. Classification with the Luria-Nebraska neuropsychological battery: An application of cluster and ipsative profile analysis. Arch Clin Neuropsychol. 1987;2:215-235.

13. Moses JA Jr, Purisch AD. The evolution of the Luria-Nebraska neuropsychological battery. In: Goldstein G, Incagnoli TM, editors. Contemporary approaches to neuropsychological assessment. New York, NY: Plenum; 1997. p. 131-170.

14. Luria AR. The working brain: An introduction to neuropsychology. New York, NY: Basic Books; 1973.

15. Das JP, Kirby JR, Jarman RF. Simultaneous and successive cognitive processes. New York, NY: Academic Press; 1979.

16. Kaufman AS, Kaufman NL. K-ABC: Kaufman assessment battery for children. Circle Pines, MN: American Guidance Services; 1983.

17. Reynolds CR, Kamphaus RW, Rosenthal BL, Heimenz JR. Applications of the Kaufman assessment battery for children (K-ABC) in neuropsychological assessment. In: Reynolds CR, Fletcher-Janzen E, editors. Handbook of clinical child neuropsychology. 2nd ed. New York, NY: Plenum; 1997. p. 252-269.

18. Spreen O, Strauss E. A compendium of neuropsychological tests. 2nd ed. New York, NY: Oxford University Press; 1998.

19. Das JP, Kirby JR, Jarman RF. Simultaneous and successive syntheses: An alternative model for cognitive abilities. Psychol Bull. 1975; 82:87-103.

20. Milner B. Interhemispheric differences in the localization of psychological processes in man. Br Med Bull. 1971;27:272-277.

21. Donders J. Validity of the Kaufman assessment battery for children when employed with children with traumatic brain injury. J Clin Psychol. 1992;48:225-230.

22. Morris JM, Bigler ED. Hemispheric functioning and the Kaufman assessment battery for children: Results in the neurologically impaired. Dev Neuropsychol. 1987;3:67-79.

23. Gutentag S, Naglieri JA, Yeates K. Performance of children with traumatic brain injury on the Cognitive Assessment System. Assessment. 1998;5:263-272.

24. Das JP, Davis B, Alexander J, Parrila RK, Naglieri JA. Cognitive decline due to aging among persons with Down syndrome. Res Dev Disabil. 1995; 16:461-478.

25, Wysocki T, Harris MA, Mauras N, et al. Absence of adverse effects of severe hypoglycemia on cognitive function in school-aged children with diabetes over 18 months. Diabetes Care. 2003;26:1100-1105.

26. Ryan JP, Atkinson TM, Dunham KT. Sports-related and gender differences on neuropsychological measures of frontal lobe functioning. Clin J Sport Med. 2004;14:18-24.

27. Davis CL, Tomporowski PD, Boyle CA, et al. Effects of aerobic exercise on overweight children's cognitive functioning: A randomized controlled trial. Res Q Exercise Sport. 2007;78:510-519.

28. Haddad FA. Planning versus speed: An experimental examination of what Planned Codes of the Cognitive Assessment System measures. Arch Clin Neuropsychol. 2004;19:313-317.

29. Perez-Alvarez F, Timoneda-Gallart C, Baus-Rosell J. Topiramate and epilepsy in the light of Das-Naglieri Cognitive Assessment System. Rev Neurologica. 2006;42:3-7.

30. Mack CL, Zelko FA, Lokar J, et al. Surgically restoring portal blood flow to the liver in children with primary extrahepatic portal vein thrombosis improves fluid neurocognitive ability. Pediatrics. 2006;117:405-412.

31. Perez-Alvarez F, Timoneda-Gallart C. PASS neurocognitive dysfunction in attention deficit. Rev Neurologica 2001;32:30-37. 
32. Jordaan H, Shaw-Ridley G, Serfontein J, Orelowitz K, Monaghan N. Cognitive and linguistic profiles of specific language impairment and semantic-pragmatic disorder in bilinguals. Folia Phoniatr Logo. 2001;53:153-165.

33. Van Luit JE, Kroesbergen EH, Naglieri JA. Utility of the PASS theory and cognitive assessment system for Dutch children with and without ADHD. J Learn Disabil. 2005;38:434-439.

34. Naglieri JA, Goldstein S, Delauder BY, Schwebach A. Relationships between the WISC-III and the Cognitive Assessment System with Connor's rating scales and continuous performance tests. Arch Clin Neuropsychol. 2005;20:385-401.

35. Eilam G. The philosophical foundations of Alexandr R. Luria's neuropsychology. Sci Context. 2003;16:551-577.

36. Wertsch JV, Tulviste P. Lev Semyonovich Vygotsky and contemporary developmental psychology. In: Parke RD, Ornstein PA, Rieser JJ, ZahnWaxler C, editors. A century of developmental psychology. Washington, DC: American Psychological Association; 1994. p. 333-355.

37. Miller GA, Galanter EH, Pribram KH. (1960). Plans and the structure of behavior. New York, NY: Holt, Rinehart and Wilson; 1960.

38. Meccaci L. Luria: A unitary view of human brain and mind. Cortex. 2005;41:816-822.

39. Tsunoda T. The Japanese brain: Uniqueness and universality. Tokio, Japan: Taishukan; 1985.

40. Ashman F, Das JP. Relation between planning and simultaneoussuccessive processing. Percept Motor Skill. 1980;51:371-382.

41. Das JP, Kar BC, Parrila RK. Cognitive planning: The psychological basis of intelligent behaviour. Thousand Oaks, CA: Sage Publications; 1996.

42. Luria AR, Tsvetkova LS. The neuropsychological analysis of problems solving. Orlando, Fl: Deutsch Press; 1990.

43. Goldberg E. Contemporary neuropsychology and the legacy of Luria. Hillsdale, NJ: Lawrence Erlbaum and Associates; 1990.

44. Shallice T. From neuropsychology to mental structure. Cambridge, UK: Cambridge University Press; 1987.

45. Stuss DT, Benson DF. The frontal lobes. New York, NY: Raven Press; 1986.

46. Stuss DT, Knight RT. Principles of frontal lobe function. New York, NY: Oxford University Press; 2002.

47. Moruzzi G, Magoun HW. Brain stem reticular formation and the activation of the EEG. Electroen Clin Neuro. 1949;1:455-473.

48. Steriade M. Arousal: Revisiting the reticular activating system. Science. 1996;272:225-226.

49. Kruk ZL, Pycock CJ. Neurotransmitters and drugs. 3rd ed. New York, NY: Chapman and Hall; 1991.

50. Kandel ER. Disorders of mood: Depression, mania, and anxiety disorders. In: Kandel ER, Schwartz JH, Jessell TM, editors. Principles of Neural Science. 4th ed. New York, NY: McGraw-Hill; 2000. p. 1209-1226.

51. Heilman KM, Watson RT, Valenstein E. Neglect and related disorders. In: Heilman KM, Valenstein E, editors. Clinical neuropsychology. 4th ed. New York, NY: Oxford University Press; 2003. p. 296-346.

52. Sechenov IM. Physiology of the nervous centers. 2nd ed. Moscow, USSR: Izd. Akad. Med; 1891. (Reprinted in 1952).

53. Luria AR. The origin and cerebral organization of man's conscious action. Proceedings of the Nineteenth International Congress of Psychology. 1971;19:37-52.

54. Luria AR, Artem'eva EY. Two approaches to an evaluation of the reliability of psychological evaluation. Sov Psychol. 1972;8:271-282.

55. Pavese A, Coslett HB, Saffran E, Buxbaum LJ. Limitations of attentional orienting: Effects of abrupt visual onsets and offsets on the naming of two objects in a patient with simultanagnosia. Neuropsychologia. 2002;40:1097-1103.

56. Lie E, Coslett HB. The effect of gaze direction on sound localization in brain-injured and normal adults. Exp Brain Res. 2006;168:322-336.

57. Stuss DT, Benson DF. The frontal lobes and language. In: Goldberg E, Editor. Contemporary neuropsychology and the legacy of Luria. Hillsdale, NJ: Lawrence Erlbaum Associates; 1990. p. 29-49.
58. Broadbent D. Perception and communication. London, UK: Pergamon; 1958

59. Treisman A. Features and objects: The fourteenth Bartlett memorial lecture. QJ Exp Psychol-A. 1998;40:201-237.

60. Peterson MA, Rhodes G. Perception of faces, objects, and scenes: Analytic and holistic processes. New York, NY: Oxford University Press; 2003.

61. Huttenlocher J, Higgins ET. On reasoning, congruence and other matters. Psychol Rev. 1972;79:420-427.

62. Wechsler D. The measurement an appraisal of adult intelligence. Baltimore, MD: Williams and Wilkins; 1958

63. Paivio A. Mental imagery in associative learning and memory. Psychol Rev. 1969;76:241-263.

64. French J, Ekstrom R, Price L. Kit of reference tests for cognitive factors. Princeton, NJ: Educational Testing Services; 1963.

65. Benton AL. A visual retention test for clinical use. New York, NY: Psychological Corporation; 1946.

66. Graham FK, Kendall BS. Memory-for-designs test: Revised general manual. Percept Motor Skill. 1960;11:147-188.

67. Raven JC. Guide to the standard progressive matrices. London, UK: H.K. Lewis; 1960.

68. Sperling G. The information available in brief visual presentations. Psychol Monogr. 1960;74:(11,Whole No. 498).

69. Birch HG, Belmont L. Auditory-visual integration in normal and retarded readers. Am J Orthopsychiatry. 1964;36:852-861.

70. Paivio A, Yuille JC, Madigan SA. Concreteness, imagery, and meaningfulness values for 925 nouns. J Exp Psychol. 1968;76:1-25.

71. Paivio A. Imagery and memory. In: Gazzaniga MS, editor. The cognitive neurosciences. Cambridge, MA: MIT Press; 1995. p. 977-986.

72. Jakobson R. Studies on child language and aphasia. The Hague: Mouton; 1971.

73. Luria AR. Basic problems in neurolinguistics. The Hague: Mouton; 1976.

74. Bournot-Trites M, Jarman RF, Das JP. Luria's language theory within a cognitive theory: A Canadian perspective. Aphasiology. 1995; 9:123-135.

75. Sagi D, Julesz B. "Where" and "what" in vision. Science. 1985;228: 1217-1219.

76. Treisman A. Feature binding, attention and object perception. Philos T Roy Soc B. 1998;353:1295-1306.

77. Behrmann M, Winocur G, Moscovitch M. Dissociations between mental imagery and object recognition in a brain-damaged patient. Nature. 1992;359:636-637.

78. Behrmann M. Neuropsychological approaches to perceptual organization: Evidence from visual agnosia. In: Peterson MA, Rhodes G, editors. Perception offaces, objects and scenes: Analytic and holistic processes. New York, NY: Oxford University Press; 2003. p. 295-334.

79. Farah MJ. Visual agnosia. 2nd ed. Cambridge, MA: MIT Press; 2004.

80. Navon D. Forest before tress: The precedence of global features in visual perception. Cognitive Psychol. 1977;9:353-383.

81. Robertson LC, Lamb MR, Knight RT. Effects of lesions of the temporalparietal junction on perceptual and attentional processing in humans. J Neurosci. 1988;8:3757-3769.

82. Robertson LC, Lamb MR. Neuropsychological contributions to theories of part/whole organization. Cognitive Psychol. 1991;23:299-330.

83. Robertson LC. Space, objects, minds and brain. New York, NY: Psychology Press; 2004.

84. Yamaguchi S, Yamagata S, Kobayahi S. Cerebral asymmetry of the "topdown" allocation of attention to global and local features. J Neurosci. 2000;20:1-5

85. Balint R. Seelenlahhmung des 'Schauens', optische Ataxie, raumliche Storung der Aummerksamkeit. Monatsschr Psychiatr Neurol. 1909;25: 5-81. (Translated in Cognitive Neuropsych. 1995;12:265-281.)

86. Luria AR. Disorders of "simultaneous perception" in a case of bilateral occipito-parietal brain injury. Brain. 1959;82:437-449.

87. Luria AR, Pravdina EN, Yarbus AL. Disorders of ocular movement in a case of simultanagnosia. Brain. 1963;86:219-228. 
88. Coslett HB, Saffran E. Simultanagnosia: To see but not to see. Brain. 1991;113:1523-1545.

89. Aysto S, Hanninen R. Simultaneous and successive cognitive processes in brain damaged adults: Hemispheric and anterior-posterior effects. Arch Clin Neuropsychol. 1988;3:9-32.

90. McCrea SM, Buxbaum LJ, Coslett HB. Illusory conjunctions in simultanagnosia: Coarse coding of visual feature location? Neuropsychologia. 2006;44:1724-1736.

91. Luria AR. Brain disorders and language analysis. Lang Speech. 1958;1:14-34.

92. Luria AR. Traumatic aphasia. Paris, France: Mouton; 1970.

93. Graybiel AM. The basal ganglia and chunking of action repertoires. Neurobiol Learn Mem. 1998;70:119-136.

94. Poldrack RA, Willingham DT. Functional neuroimaging of skill learning. In: Cabeza R, Kingstone A, editors. Handbook of functional neuroimaging. 2nd ed. Cambridge, MA: MIT Press; 2006. p. 113-148.

95. Kim Y, Royer F, Bonstelle C, Boller F. Temporal sequencing of verbal and nonverbal materials: The effect of laterality of lesion. Cortex. 1980;16:135-143.

96. Okuhata ST, Okazaki S, Maekawa H. Differential topographic pattern of EEG coherence between simultaneous and successive coding tasks. Int J Psychophysiol. 2007;66:66-80.

97. Okuhata ST, Okazaki S, Maekawa H. EEG coherence pattern during simultaneous and successive processing tasks. Int J Psychophysiology. 2008 Nov 5. [Epub ahead of print]

98. Singer W. Time as a coding space in the cerebral cortex. In: Kanwisher N, Duncan J, editors. Functional neuroimaging of visual cognition: Attention and performance XX. New York, NY: Oxford University Press; 2004. p. 99-123.

99. Hurley RA, Taber KH, editors. Windows to the brain: Insights from neuroimaging. Washington, DC: American Psychiatric Publishing; 2008.

100. Weiss S, Muller HM, Schack B, King JW, Kutas M, Rappelsberger P. Increased neural communication accompanying sentence comprehension. Int J Psychophysiol. 2005;57:129-141.

101. Nebes RD. Direct examination of cognitive function in the right and left hemispheres. In: Kinsbourne M, editor. Asymmetrical function of the brain. Cambridge, UK: Cambridge University Press; 1978. p. 99-137.

102. Klimesch W. EEG alpha and theta oscillations reflect cognitive and memory performance: A review and analysis. Brain Res Rev. 1999;29:169-195.

103. Weiss S, Rappesberger P. Long-range EEG synchronization during word encoding correlates with successful memory performance. Cognitive Brain Res. 2000;9:299-312.

104. Schack B, Klimesch W, Sauseng P. Phase synchronization between theta and upper alpha oscillations in a working memory task. Int $J$ Psychophysiol. 2005;57:105-114.

105. Harrington DL, Rao SM, Haaland KY, et al. (2000). Specialized neural systems underlying representations of sequential movements. J Cognitive Neurosci. 2000;12:56-77.

106. Deiber MP, Honda M, Ibanez V, Sadato N, Hallett M. Mesial motor areas in self-initiated versus externally triggered movements examined with fMRI: Effect of movement type and rate. J Neurophysiol. 1999;81:3065-3077.

107. Bhimani AA, Hlustik P, Small SL, Solodkin A. Complex motor functions in humans: Validating and extending the postulates of Alexadr R. Luria. Cog Behav Neurol. 2006;19:11-20.

108. Annett M. The binomial distribution of right, mixed and left-handedness. QJ Expl Psychol. 1967;19:327-333.

109. McCrea SM. A nonparametric study of the performance of cortical lesion patients on the Cognitive Assessment System. Arch Clin Neuropsychol. 2006;21:321-325.
110. Russell EW. A reference method for constructing neuropsychological test batteries. J Clin Exp Neuropsychol. 1987;9:376-392.

111. Yin RK. Case study research: Design and methods. 2nd ed. London, UK: Sage Publications; 1994.

112. Aldenderfer MS, Blashfield RK. Cluster analysis. Beverly Hills, CA Sage Publications; 1984.

113. Yantis S, Serences JT. Cortical mechanisms of space-based and objectbased attentional control. Curr Opin Neurobiol. 2003;13:187-193.

114. Berlucchi G, Aglioti S. Interhemispheric disconnection syndromes. In: Denes G, Pizzamiglio L, editors. Handbook of clinical and experimental neuropsychology. East Sussex, UK: Psychology Press; 1999. p. 635-670.

115. Doty RW. Unity from duality. Acta Neurobiol Exp. 2003;63:163-170.

116. Kluger BM, Heilman KM. Disruption of reciprocal coordination by a medial frontal stroke sparing the corpus callosum. Cog Behav Neurol. 2007;20:230-231.

117. Heilman KM, Valenstein E, editors. Clinical neuropsychology. 4th ed. New York, NY: Oxford University Press; 2003.

118. Salloway S, Malloy P, Cummings JL, editors. The neuropsychiatry of limbic and subcortical disorders. Washington, DC: American Psychiatric Press; 1997.

119. Grafman J. Experimental assessment of adult frontal lobe function. In: Miller BL, Cummings JL, editors. The human frontal lobes: Functions and disorders. New York, NY: Guilford Press; 1999. p. 321-344.

120. Goel V, Grafman J. Role of the right prefrontal cortex in ill-structured planning. Cognitive Neuropsychol. 2000;17:415-436.

121. Robertson LC, Knight RT, Rafal R, Shimamura AP. Cognitive neuropsychology is more than single-case studies. J Exp Psychol Learn. 1993;19:710-717.

122. Catani M, ffytche DH. The rises and falls of disconnection syndromes Brain. 2005;128:2224-2239.

123. Goebel R, Roebroek A, Kim DS, Formisano E. A framework for the investigation of directed cortical interactions: Theoretical background and application to dynamic sensorimotor mapping. In: Kanwisher N, Duncan J, editors. Functional neuroimaging of visual cognition: Attention and performance $X X$. New York, NY: Oxford University Press; 2004. p. 439-462.

124. Lewine JD, Doty RW, Astur RS, Provencal SL. Role of the forebrain commissures in bihemispheric mneumonic integration in macaques. J Neurosci. 1994;14:2515-2530.

125. Denes G, Pizzamiglio D, editors. Handbook of clinical and experimental neuropsychology. East Sussex, UK: Psychology Press; 1999.

126. McCrea SM. A multiple case study examining neuropsychological properties of the Cognitive Assessment System. Unpublished doctoral dissertation. Edmonton, Canada: University of Alberta Press; 2001.

127. McCrea SM. A cognitive-neuropsychological examination of the Das-Naglieri Cognitive Assessment System subtests: A report of three stroke cases studied longitudinally during recovery. Int $J$ Neurosci. 2009;119(4):553-599.

128. McCrea SM, Scott M. A case study of strategic infarct dementia investigated with the Cognitive Assessment System. Brain Cognition. 2002;49:207-210.

129. McCrea SM. Measurement of recovery after traumatic brain injury: A cognitive-neuropsychological comparison of the WAIS-R with the Cognitive Assessment System (CAS) in a single case of atypical language localization. Appl Neuropsychol. 2007;14:296-304.

130. Kosslyn SM, Chabris CF, Marsolek CJ, Koenig O. Categorical and coordinate spatial relations. Computational analyses and computer simulations. J Exp Psychol Hum Percept Perform. 1992;18: $562-577$ 
